\title{
Article \\ Comparison of AC and DC Nanogrid for Office Buildings with EV Charging, PV and Battery Storage
}

\author{
Ilman Sulaeman, Gautham Ram Chandra Mouli $\mathbb{D}^{\mathrm{D}}$, Aditya Shekhar* ${ }^{\mathbb{D}}$ and Pavol Bauer (D) \\ Electrical Sustainable Energy, Delft University of Technology, Mekelweg 4, 2628 CD Delft, The Netherlands; \\ ilman.sulaeman@gmail.com (I.S.); G.R.ChandraMouli@tudelft.nl (G.R.C.M.); P.Bauer@tudelft.nl (P.B.) \\ * Correspondence: a.shekhar@tudelft.nl
}

Citation: Sulaeman, I.; Chandra

Mouli, G.R.; Shekhar, A.; Bauer, P.

Comparison of AC and DC Nanogrid for Office Buildings with EV Charging, PV and Battery Storage. Energies 2021, 14, 5800. https:// doi.org/10.3390/en14185800

Academic Editor: Luis

Hernández-Callejo

Received: 4 August 2021

Accepted: 10 September 2021

Published: 14 September 2021

Publisher's Note: MDPI stays neutral with regard to jurisdictional claims in published maps and institutional affiliations.

\begin{abstract}
Future office buildings are expected to be integrated with energy intensive, inherently DC components such as photovoltaic panels (PV), electric vehicles (EV), LED lighting, and battery storage. This paper conceptualizes the interconnection of these components through a $750 \mathrm{~V}$ DC nanogrid as against a conventional three-phase $400 \mathrm{~V}$ AC system. The factors influencing the performance of a DC-based nanogrid are identified and a comparative analysis with respect to a conventional AC nanogrid is presented in terms of efficiency, stability, and protection. It is proved how the minimization of grid energy exchange through power management is a vital system design choice. Secondly, the trade-off between stability, protection, and cost for sizing of the DC buffer capacitors is explored. The transient system response to different fault conditions for both AC and DC nanogrid is investigated. Finally the differences between the two systems in terms of various safety aspects are highlighted.
\end{abstract}

Keywords: AC; DC; nanogrid; solar PV; electric vehicle; efficiency; stability; protection

\section{Introduction}

\subsection{Objective}

Utilization of Renewable Energy sources (REs) for electricity production has been developed for decades [1,2]. As reported by [3], solar PV has the highest development rate compared to other REs because solar energy is an abundant resource. At the same time, shift to environment friendly technologies has garnered interest for high power applications such as Electric Vehicle (EV) charging. While currently EVs and associated charging infrastructure is in early market penetration phase, it is expected that these will be cost competitive with internal combustion vehicles in future [4].

In this paper, the integration of the PV, EV and other appliances within an office building using an AC or DC nanogrid is compared and analyzed. The AC and DC nanogrid is also connected to the external grid. The objective of this paper is to quantify the efficiency benefits of DC nanogrid for charging EVs form PV at workplaces and identifying the maximum efficiency by looking at the energy exchange with the grid; to investigate the stability issues in DC nanogrid and the trade-offs of improving it; to offer the sizing of DC buffer capacitors which correlate to the required protection devices.

\subsection{Literature Review}

The synergistic integration of EV-PV technologies can address challenges such as grid congestion [5-7]. At the same time, Energy Storage Systems (ESS) can aid in reducing the peak loading of the grid by introducing flexibility in power demand profile [8]. Furthermore, with an proper energy management and sizing, ESS could also effectively improve the system stability and reliability $[9,10]$. PV, EV, and ESS are inherently dc in nature, and therefore, it is suggested that dc based energy exchange offers superior performance and higher efficiency as compared to ac distribution [11-13]. DC interconnection between 
EV and PV reduces a conversion step, thereby making the system more compact and efficient [14-16].

It is stated that DC nanogrid gives better controllability and possibility to implement higher voltage than in AC. Moreover, the cable losses is higher and the power transfer is lower in AC nanogrid, due to the frequency and its sinusoidal waveform [17,18]. The fault comparisons and protection strategy are also discussed in [13,19-21]. However, quantitative comparison is required in order to measure the practical advantage of DC over AC. These comparisons are very dependent on the system design and energy productionconsumption's profile. Furthermore, information about the trade-offs for DC system to have better control and fault interruption than AC system should also be addressed. Therefore, this paper develops quantitative comparison from a specific case then elaborate it to form the conclusions that embodied the general quantitative comparison.

\subsection{Research Contribution}

This paper investigates the multi-faceted trade off between efficiency, stability, and protection of AC and DC nanogrids. Different cases and sensitivity analyses are elaborated to illustrate the relation of energy mismatch (production and demand) to the nanogrids' efficiency trend. Furthermore, fault and protection behavior are also compared to describe the fundamental differences of both $\mathrm{AC}$ and DC nanogrids. The comparisons focus on the following aspects:

- System efficiency: System efficiency correlates to the system electrical energy autarky (EEA) and the annual saving. EEA indicates the independency of the system to the electricity grid without taking into account the heat load demand and fuel consumption [22]. More efficient system means that there is less losses occurring in the system's components (e.g., converters, cables, etc.). Therefore, more energy can be utilized for the loads and less energy is required from external grid. In the other case, when the PV generates more energy than demanded, there will be more excess energy that can be sold to the grid.

- Control: Figure 1 shows two types of building's interconnection with PV, EV, battery, loads, and grid. In AC nanogrid, as shown in Figure 1a, the utility grid is directly connected to the nanogrid. Therefore, changes in demand or production in the office will not affect the AC nanogrid since the AC grid is assumed as a very stable source. Even though the system can be considered to be very stable; voltage, frequency, and reactive power have to be controlled in order to maintain the stability of the system. DC nanogrid, as shown in Figure 1b, is more challenging in terms of control. Although there is no frequency and reactive power issues, the AC grid is not directly connected to the nanogrid, but through an AC/DC bidirectional converter. This converter plays a significant role to maintain the stability of the DC nanogrid.

- Protection and Safety: Different nature of AC and DC currents necessities different protection mechanism for the two systems. The presence of frequency and zero crossing in AC nanogrid makes the system easier to be dealt with during a fault condition. The inductance of the cables within the system will lower the fault current and the zero crossing helps extinguishing the arc automatically. However, absence of current zero crossing in DC nanogrid makes both series and parallel electric arcs a concern [23,24]. During short circuits, the fault current in DC is higher and the absence of zero crossing makes the arc persist which is hazardous. 


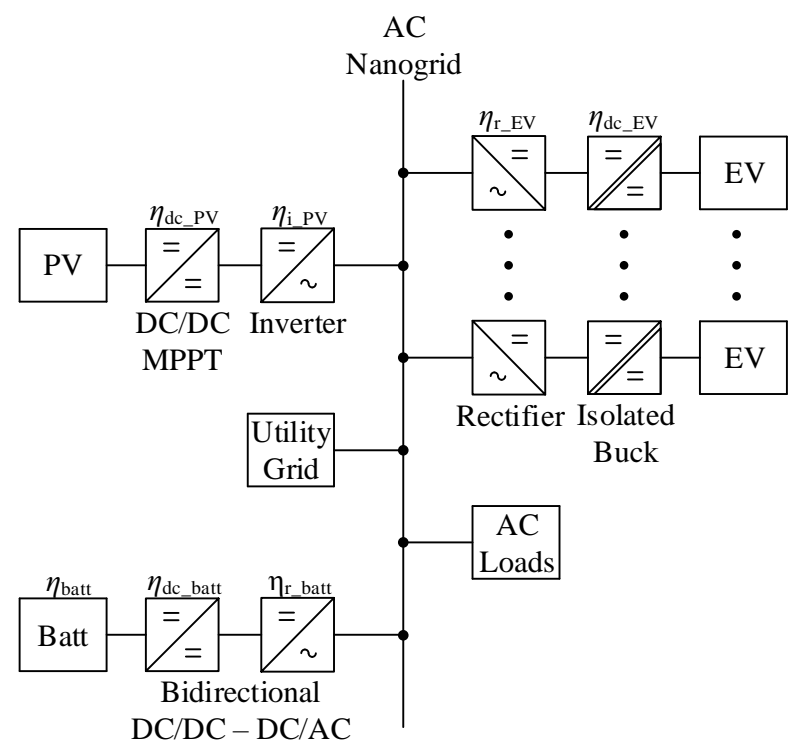

(a) AC nanogrid.

DC

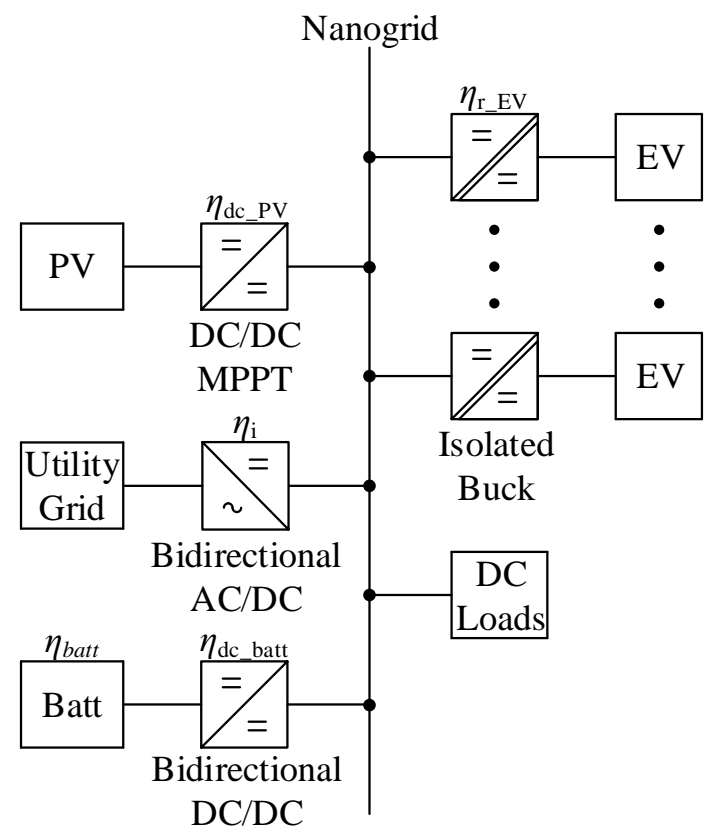

(b) DC nanogrid.

Figure 1. System architecture.

\subsection{Paper Organization}

This paper discusses the AC and DC nanogrids in an office building with PV and EVs and compares both interconnections in several aspects. In the beginning of this paper the introduction of the paper is briefed. Section 2, describes the system's specification that are being compared. In Section 3, the results and analysis of the comparison in terms of system efficiency are presented while Section 4 discusses the result and analysis on system's control and protection. Then, Section 5 concludes the comparison of AC and DC nanogrids in aforementioned aspects. 


\section{System Description}

\subsection{System Architecture}

The topology for $3 \phi 400 \mathrm{~V} \mathrm{AC}$ and $750 \mathrm{~V}$ assymetrical monopolar DC interconnection are shown in Figure 1a,b respectively.

The shown architectures are referred to as nanogrid because the components connected to the common bus in the system can act as a small sub-unit within the existing ac utility grid, thereby preserving a degree of controllability in energy exchange through chosen power management scheme. Different component blocks such as EV, PV, building loads, battery ESS (Batt) and the utility grid are interconnected with a common AC or DC bus. Depending on the output type, appropriate AC/DC, DC/DC and DC/AC converter blocks are used for this integration. It can be observed that the $\mathrm{AC}$ nanogrid has an extra conversion stage for EV, PV and Batt integration, while DC nanogrid requires an extra Active Front End (AFE) AC/DC converter for energy exchange with the utility grid. It can be shown the ESS can significantly improve the efficiency of dc distribution in commercial building as compared to ac by minimizing the internal nanogrid power mismatches and energy exchange via AFE [25].

\subsection{System Size and Power Profiles}

\subsubsection{Office loads}

For the quantitative study, this paper focuses on a case study of a office building in the Netherlands. A typical three floors Dutch office building load is used for the simulations with an average of 35 working persons was adapted from [26]. The energy consumption of one working day is $270 \mathrm{kWh}$ with peak demand of $22 \mathrm{~kW}$. It is assumed that during weekends the load is only $30 \%$ weekdays as shown in Figure 2.

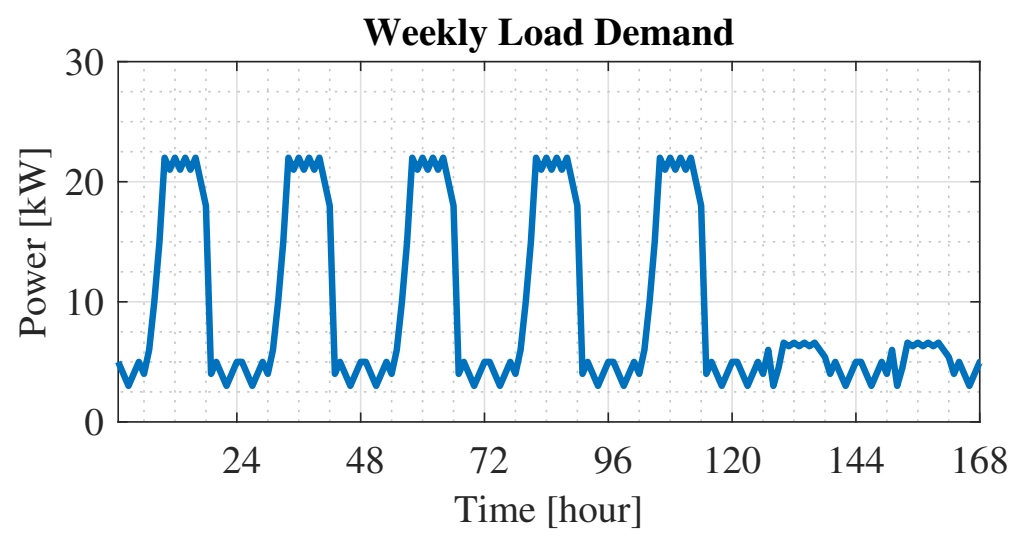

Figure 2. Office power consumption with five weekdays and two days of weekend.

The considered loads are assumed directly connected to the respective AC and DC nanogrid. This implies that in case of DC, such loads must be re-dimensioned to be 'DC ready' [27-29]. The associated benefits of this strategy in the favour of DC systems are not considered in this paper. Typically, the office appliances of both AC and DC characteristics are integrated to the $\mathrm{AC}$ grid with relevant conversion device. This conventional strategy will lead to additional conversion stage in case of DC nanogrid and is not considered in this paper. Consequently, the presented results intend to capture the performance benefits associated with energy exchange between ESS, EV, PV and the grid. The EV and ESS sizes and configurations are based on [30] with rated capacity of $19.6 \mathrm{kWh}(287 \times 38,1.2 \mathrm{~V}$, $1.5 \mathrm{Ah}$; Li-ion battery) and $22.9 \mathrm{kWh}(84 \times 35,6 \mathrm{~V}, 1.3 \mathrm{Ah}$; Li-ion battery).

\subsubsection{EV Charging Profile}

EV charging profile depends on daily activities of the office, such as working hours, traffic, company policies, user behaviour, etc. In this paper, the EVs are owned by the employee and simulated with five different charging profiles. The five charging profiles 
have different arrival and departure time that is adapted from [31] and modified such that the EVs' state of charge (SOC) are greater than $90 \%$ at the departure time. The charging power for all the EVs is averaged in a way that each EV is charged in a constant power when parked and the charging power are identical for each working day throughout the year. This corresponds to $45.2 \mathrm{kWh}$ demand every working days or $11.8 \mathrm{MWh}$ in a year (5 days a week) for the case of five EVs with different charging profiles. Figure 3a shows the EVs charging profile for each EV during the week, with the last two days as weekend. Compared to weekdays, office power consumption is much less and there is no EV charging demand during weekends. This does not necessarily result in lower grid energy exchange, because there is a possibility that more energy is sent to the grid during high PV generation.

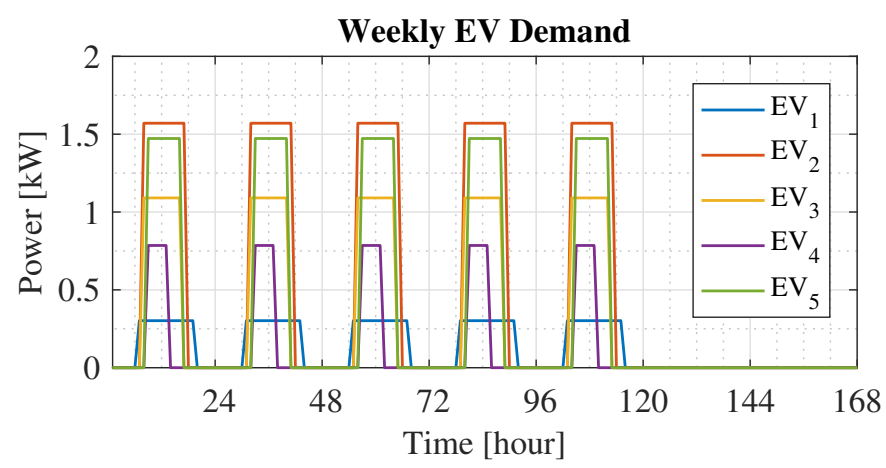

(a) EV charging power with five weekdays and two days of weekend.

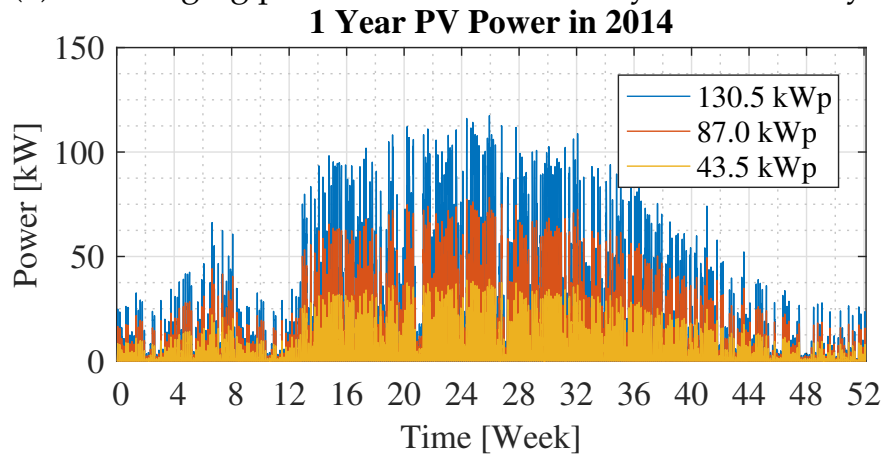

(b) PV generation profile.

Figure 3. Typical EV and PV power profiles for office workplace.

\subsubsection{PV Generation Profile}

In order to estimate the PV generation output, irradiation data is taken from the KMNI (Koninklijk Nederlands Meteorologisch Instituut) at the Cesar Observatory (51.971 N, $4.927 \mathrm{E}$ ) and used as an input for the PV model developed in [32]. The simulations use generation data of $435 \mathrm{Wp}$ module for the whole year of 2014. 20 modules are connected in series to form a string $(8.7 \mathrm{kWp})$, which corresponds to $7.1 \mathrm{MWh}$ generation in a year. Several number of string are configured to have different PV capacities as shown in Figure $3 b$.

\section{Comparison of Average Operating Efficiency}

The difference in conduction and converter losses between AC and DC nanogrids is quantified in this section for varying energy mismatches.

\subsection{Assumptions}

The following assumptions are made to compare the simulated efficiency of AC and DC nanogrid:

- The battery ESS is constrained between 10\% to $90 \%$ depth of discharge.

- The efficiency of each conversion step is set to a vlue of $98 \%$. 
- Conduction losses associated with power distribution in the AC nanogrid are represented with efficiency $\eta_{\text {cond,AC }}=99 \%$. This includes power losses in cables, protection devices, busbars, and contact point resistances.

- While the PV data for an entire year is considered to account for the seasonal/daily variation in power profile, weekdays-weekends load and EV profile used over the year for the presented results. Therefore some deviation due to seasonal variation is expected, which is not considered in this paper.

\subsection{AC and DC Conduction Losses}

Conduction losses for DC nanogrid $\left(P_{\text {loss,DC }}\right)$ is lower than that for $\mathrm{AC}\left(P_{\text {loss, }, \mathrm{AC}}\right)$ because the current flowing through various interconnections is lower for the given bus power $\left(P_{\mathrm{op}}\right)[18]$. This can be inferred from (1) and (2) as the operating DC bus voltage $U_{\mathrm{DC}}^{2}$ is selected equal to the peak AC voltage $\left(E_{\max }=\sqrt{2} E_{\mathrm{r} . \mathrm{m} . \mathrm{s}}\right)$.

$$
\begin{aligned}
& P_{\text {loss }, \mathrm{DC}}=2 R_{\text {cond, } \mathrm{DC}} I_{\mathrm{DC}}^{2}=2 R_{\text {cond, } \mathrm{DC}} \frac{P_{\mathrm{op}}^{2}}{U_{\mathrm{DC}}^{2}} \\
& P_{\text {loss }, \mathrm{AC}}=3 R_{\text {cond, } \mathrm{AC}} I_{\mathrm{AC}}^{2}=3 R_{\text {cond, } \mathrm{AC}} \frac{P_{\mathrm{op}}^{2}}{\left(\sqrt{3} E_{\mathrm{ll}, \mathrm{r} \cdot \mathrm{m} . \mathrm{s}} \cos \phi\right)^{2}}
\end{aligned}
$$

While the actual system level conduction losses are a function of length dependent cable resistance, connection points and protection devices, this paper assumes that $P_{\text {loss,cond }}$ are related to $P_{\mathrm{op}}$ with a fixed efficiency $\eta_{\text {cond }}$ as shown in (3).

$$
P_{\text {loss }, \text { cond }}=\left(1-\eta_{\text {cond }}\right) \times P_{\text {op }}
$$

For the assumed $\eta_{\text {cond,ac }}=99 \%$, the conduction efficiency of DC nanogrid $\left(\eta_{\text {cond,dc }}\right)$ can be found by dividing (1) and (2) and substituting (3), as given by (4).

$$
\eta_{\text {cond,dc }}=1-\left[\frac{2}{3} \times\left(\frac{\sqrt{3} E_{11, r . m . s} \cos \phi}{U_{D C}}\right)^{2} \times\left(1-\eta_{\text {cond }, a c}\right)\right]
$$

\subsection{System Efficiency}

Figure 1a,b show different number of conversion steps for power that flows in the system. For example, the power flowing from PV to load, the associated path has two converter stages for AC nanogrid, while only two in case of DC. All conversion steps for each power flow are summarized in Table 1. There is only one path when AC nanogrid has less conversion steps, which is from the grid to the office appliances. Therefore, it is possible for AC nanogrid to have higher efficiency than DC if the power flowing from the grid to office appliances is dominant compared to the other power flows.

Table 1. Conversion steps.

\begin{tabular}{cccccc}
\hline \multirow{2}{*}{ Power Flows } & \multicolumn{2}{c}{ Conversion Steps } & & \multicolumn{2}{c}{ Conversion Steps } \\
\cline { 2 - 3 } \cline { 5 - 6 } & AC & DC & & AC & DC \\
\hline $\mathrm{PV} \rightarrow$ load & 2 & 1 & Batt $\rightarrow$ load & 2 & 1 \\
$\mathrm{PV} \rightarrow$ EV & 4 & 2 & Batt $\rightarrow$ EV & 4 & 2 \\
$\mathrm{PV} \rightarrow$ grid & 2 & 2 & Grid $\rightarrow$ load & - & 1 \\
$\mathrm{PV} \rightarrow$ batt & 4 & 2 & Grid $\rightarrow$ EV & 2 & 2 \\
\hline
\end{tabular}

These power flows can be formulated into equations, including the losses in cables and converters, to calculate the real power that are used in the system. The equations are used in the simulations to obtain the power at all time and eventually the system efficiency. 


\subsubsection{Power Balance Equations}

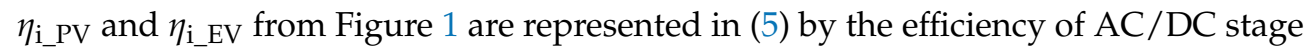
for PV and EV. $\eta_{\mathrm{DC} \_\mathrm{PV}}$ and $\eta_{\mathrm{DC} \_\mathrm{EV}}$ are the efficiency of DC/DC converter attached to PV and EV. $\eta_{\mathrm{r}_{-} \mathrm{EV}}$ is the efficiency of rectifier attached to EV. $\eta_{\mathrm{i}}$ and $\eta_{\mathrm{r}}$ are the efficiency of bidirectional AC/DC attached to grid. $P_{\text {Grid }}$ is the power fed/drawn to/from the grid. $P_{\mathrm{Load}, \mathrm{AC}}, P_{\mathrm{Load}, \mathrm{DC}}, P_{\mathrm{EV}}$ are power demands for AC, DC appliances, and EVs. $P_{\mathrm{PV}}$ is power generated from $P V$.

The power exchanged with the utility grid in case of AC nanogrid $\left(P_{\text {Grid, } A C}\right)$ is given by (5).

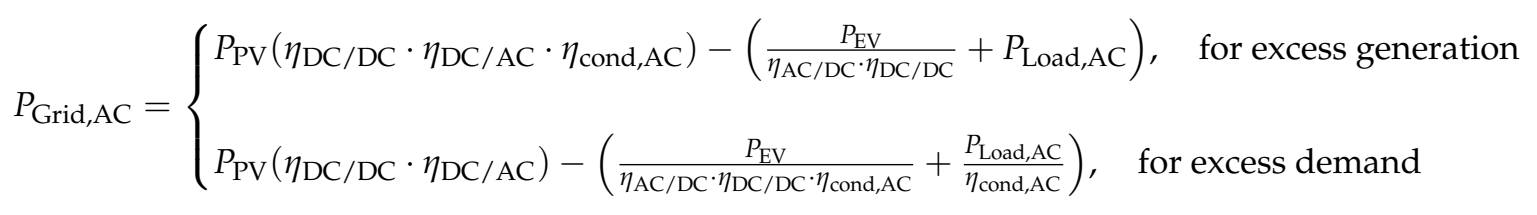

Similarly, the power exchanged with the utility grid in case of DC nanogrid $\left(P_{\text {Grid,DC }}\right)$ is given by (6).

$$
P_{\mathrm{Grid}, \mathrm{DC}}=\left\{\begin{array}{l}
{\left[P_{\mathrm{PV}}\left(\eta_{\mathrm{DC} / \mathrm{DC}} \cdot \eta_{\mathrm{cond}, \mathrm{DC}}\right)-\left(\frac{P_{\mathrm{EV}}}{\eta_{\mathrm{DC} / \mathrm{DC}}}+P_{\mathrm{Load}, \mathrm{DC}}\right)\right] \cdot \eta_{\mathrm{DC} / \mathrm{AC}}, \quad \text { for excess generation }} \\
{\left[P_{\mathrm{PV}}\left(\eta_{\mathrm{DC} / \mathrm{DC}}\right)-\left(\frac{P_{\mathrm{EV}}}{\eta_{\mathrm{DC} / \mathrm{DC}} \cdot \eta_{\mathrm{cond}, \mathrm{DC}}}+\frac{P_{\mathrm{Load}, \mathrm{DC}}}{\eta_{\mathrm{cond}, \mathrm{DC}}}\right)\right] / \eta_{\mathrm{AC} / \mathrm{DC},} \text { for excess demand }}
\end{array}\right.
$$

Throughout the day, the power flows according to the generation and demand conditions and also the power management. Based on those, the energy during the day can be calculated and classified as the energy demanded by the load ( $\left.E_{\text {Load }}\right)$, energy used to charge the EVs $\left(E_{\mathrm{EV}}\right)$, energy produced by $\mathrm{PV}\left(E_{\mathrm{PV}}\right)$, the energy that is exported during excess generation $\left(E_{\mathrm{Grid}, \mathrm{exp}}\right)$ and imported from the grid when demand is higher than PV generation $\left(E_{\mathrm{Grid}, \mathrm{imp}}\right)$. Therefore, the cumulative system efficiency $\left(\eta_{\text {sys }}\right)$ can be calculated using (7).

$$
\eta_{\text {sys }}[\%]=100 \times \frac{E_{\mathrm{Load}}+E_{\mathrm{EV}}+E_{\mathrm{Grid}, \mathrm{exp}}}{E_{\mathrm{PV}}+E_{\mathrm{Grid}, \mathrm{imp}}}
$$

\subsubsection{Sensitivity Analysis with Varying PV and EV Energy}

Power management (Figure 4a) is performed for one year of operation and the cumulative efficiency is computed from (7) for different PV and EV energy. The results are represented in terms of efficiency difference $\left(\eta_{\text {diff }}=\eta_{\text {sys,DC }}-\eta_{\text {sys,AC }}\right)$ as in Figure $4 \mathrm{~b}$. A positive $\eta_{\text {diff }}$ implies that DC nanogrid has relatively higher cumulative system efficiency over the year of operation.

It can be observed, the relative efficiency of DC nanogrid improves with increasing EV demand as well as higher PV generation. This supports the intuitive understanding that both PV and EV are DC in nature and respective power flows are associated with lower conversion stages. In other words, we want to highlight that if the objective function is to minimize the energy exchange with a predominantly AC utility grid (and therefore maximizes the renewable energy consumption), DC based energy exchange within the workplace is preferred.

The correlation between grid energy exchange and higher relative efficiency of DC nanogrid is observed in Figure 5. The optimum (graph's knee) $\eta_{\text {diff }}$ is obtained at the lowest grid energy exchange. This is because the energy flowing from PV to EVs and office appliances are dominant compared to the energy imported from the AC grid. In AC nanogrid, the energy suffers more conversion steps when the energy from the grid to EVs and office appliances are replaced by PV. Therefore, AC nanogrid has the lowest efficiency when most of the loads are powered by the PV. 


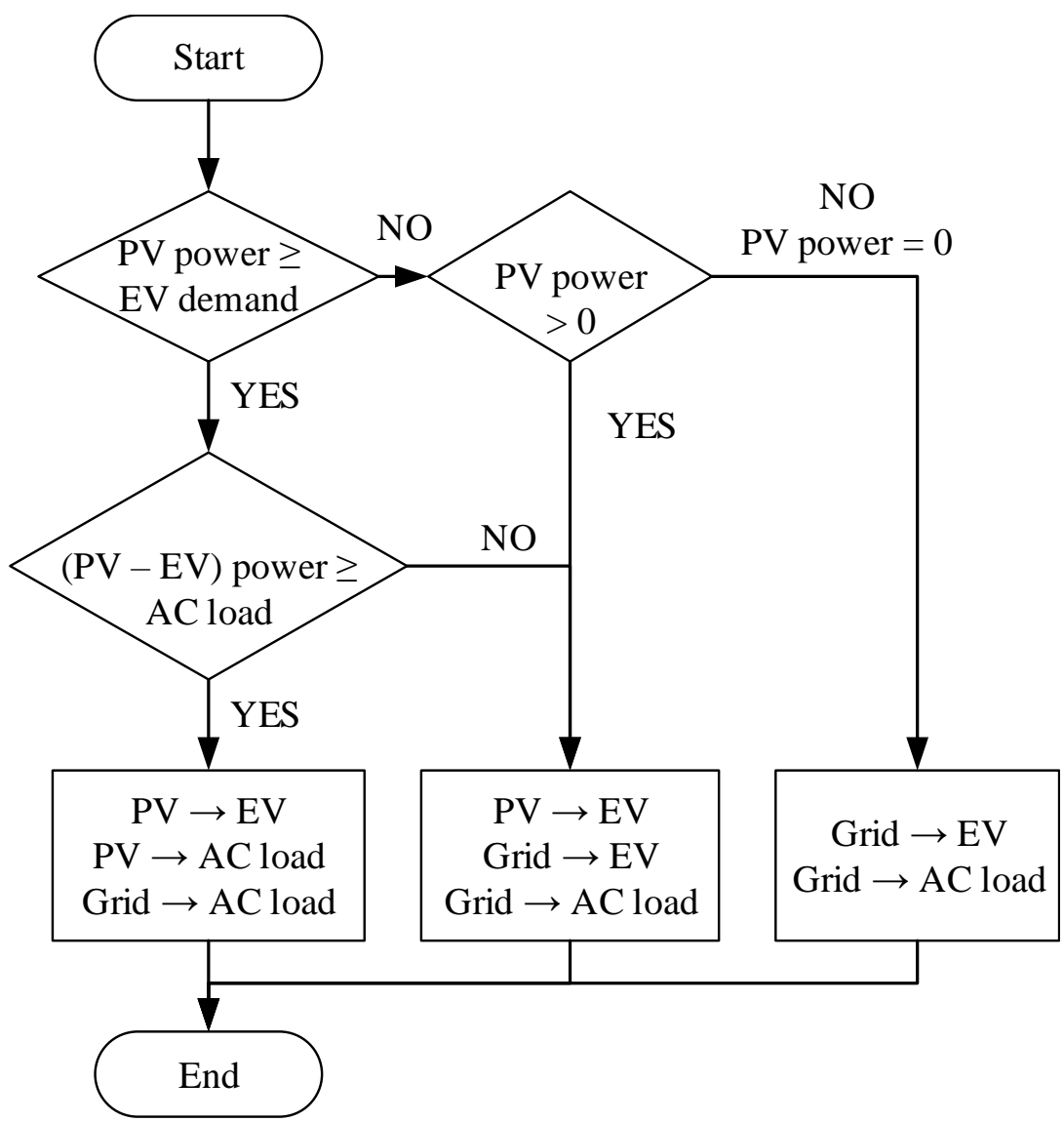

(a) Power management with fixed EV charging profile.

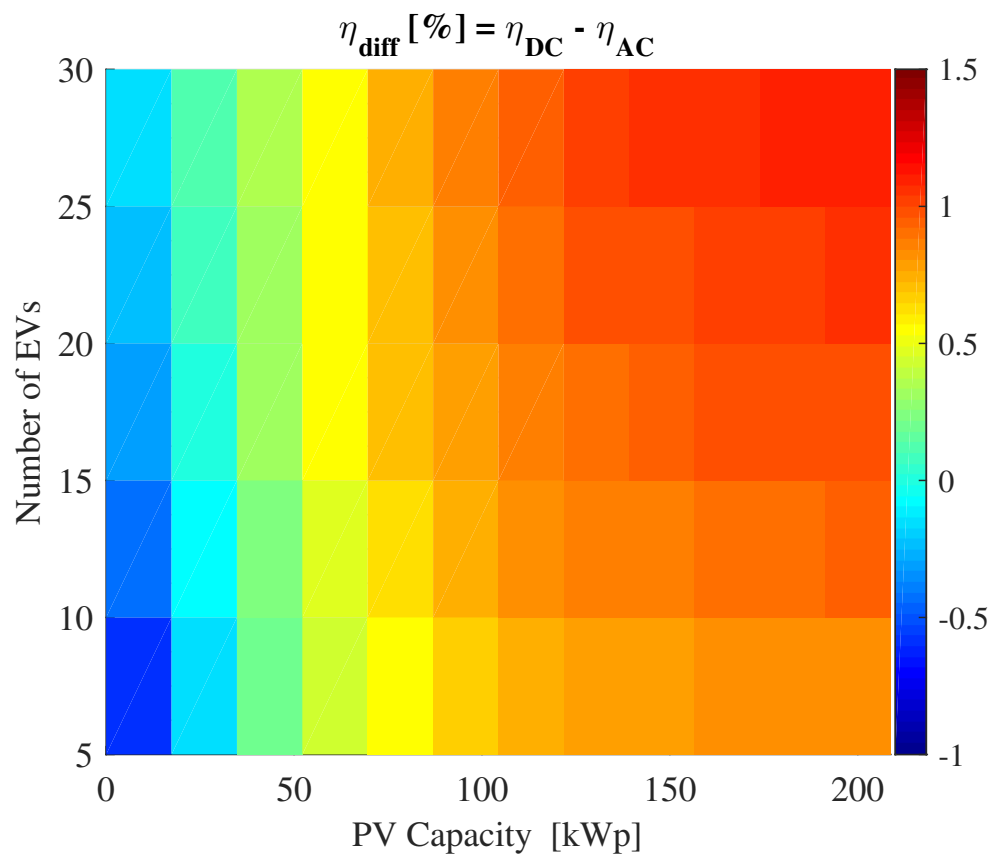

(b) Relative efficiency of DC nanogrid over AC.

Figure 4. Relative efficiency with corresponding power management. 


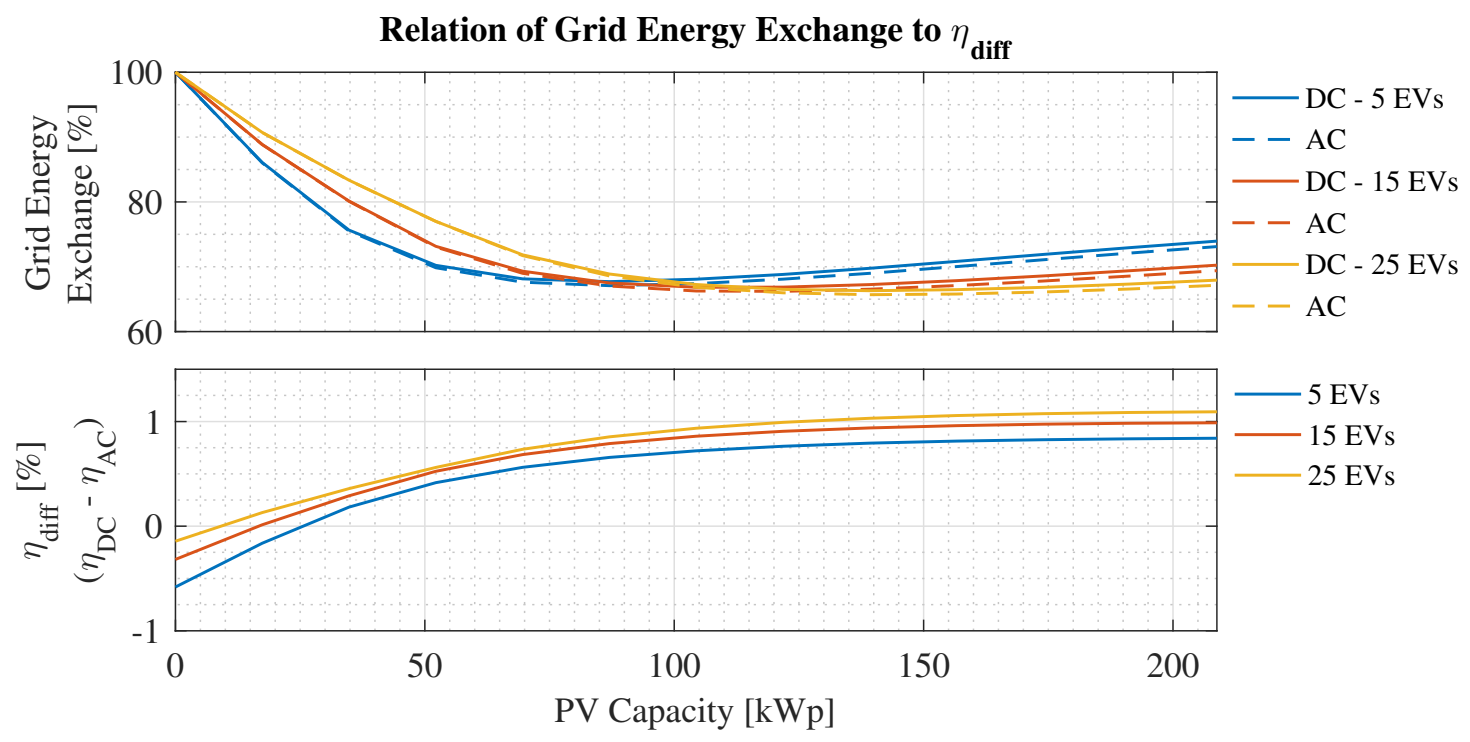

Figure 5. Correlation of grid exchange and relative efficiency.

The $\eta_{\text {diff }}$ is negative at low PV generation because, there is a conversion step from the grid to DC nanogrid while none in AC. DC nanogrid will drawn more energy, which lead to lower efficiency. However, at a certain EV demand and office appliances ratio, the DC nanogrid will have higher efficiency because the difference in conduction losses (see Equation (4)) becomes dominant than the conversion loss of the grid to DC nanogrid.

\subsubsection{Impact of battery}

In the case when $22.9 \mathrm{kWh}$ battery is integrated in the system, the efficiency trend in both nanogrids are shifted down due the additional the conversion losses and the roundtrip loss (assumed as 98\%). Power from/to the battery is formulated as in (5) and (6), while the changes in efficiency is shown in Figure 6.

- AC nanogrid

$P_{\mathrm{Batt}, \mathrm{AC}}=\left\{\begin{array}{l}{\left[P_{\mathrm{PV}}\left(\eta_{\mathrm{DC} / \mathrm{DC}} \cdot \eta_{\mathrm{DC} / \mathrm{AC}} \cdot \eta_{\mathrm{cond}, \mathrm{AC}}\right)-\left(\frac{P_{\mathrm{EV}}}{\eta_{\mathrm{AC} / \mathrm{DC} \cdot} \eta_{\mathrm{DC} / \mathrm{DC}}}+P_{\mathrm{Load}, \mathrm{AC}}\right)\right] \cdot \eta_{\mathrm{DC} / \mathrm{DC}} \cdot \eta_{\mathrm{AC} / \mathrm{DC}}} \\ \quad \begin{array}{l}\quad \text { for charging } \\ \quad, \quad \text { for discharging }\end{array}\end{array}\right.$

- DC nanogrid

$$
P_{\mathrm{Batt}, \mathrm{DC}}=\left\{\begin{array}{l}
{\left[P_{\mathrm{PV}}\left(\eta_{\mathrm{DC} / \mathrm{DC}} \cdot \eta_{\mathrm{cond}, \mathrm{DC}}\right)-\left(\frac{P_{\mathrm{EV}}}{\eta_{\mathrm{DC} / \mathrm{DC}}}+P_{\mathrm{Load}, \mathrm{DC}}\right)\right] \cdot \eta_{\mathrm{DC} / \mathrm{DC},} \text { for charging }} \\
{\left[P_{\mathrm{PV}}\left(\eta_{\mathrm{DC} / \mathrm{DC}}\right)-\left(\frac{P_{\mathrm{EV}}}{\eta_{\mathrm{DC} / \mathrm{DC}} \cdot \eta_{\mathrm{cond}, \mathrm{DC}}}+\frac{P_{\mathrm{Load}, \mathrm{DC}}}{\eta_{\mathrm{cond}, \mathrm{DC}}}\right)\right] / \eta_{\mathrm{DC} / \mathrm{DC},} \text { for discharging }}
\end{array}\right.
$$

Higher losses is found in AC nanogrid due to more conversion steps going in and out the ESS. In office buildings, the peak demand occurred at the same time with the PV generation. Therefore, it is better to size the PV in a way that it matches the average office demand (and EVs) rather than adding a battery system. Instead of acting as a storage, the battery can be used as a temporary back-up or to regulate the nanogrid voltage, which can be done with much lower capacity, hence lowering the cost. 


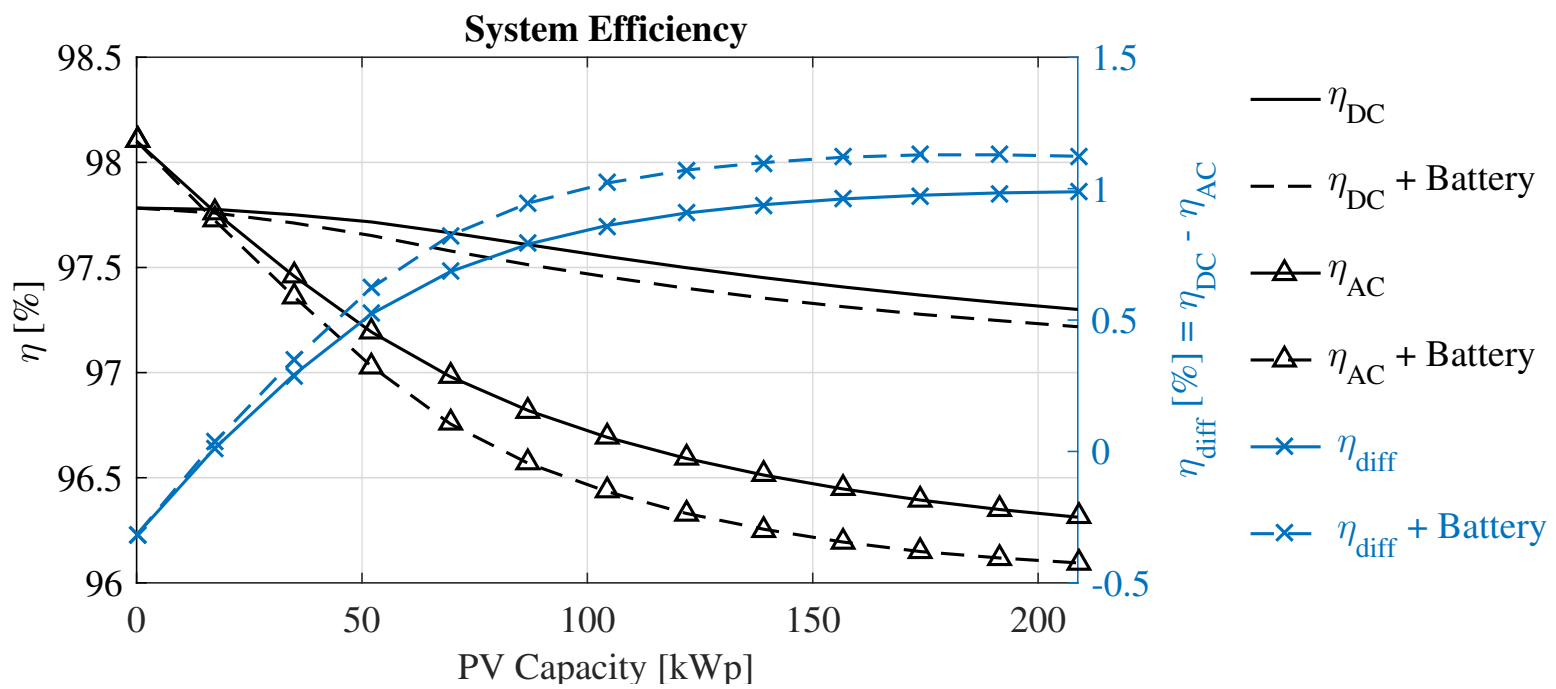

Figure 6. Efficiency with and without energy storage - example of 15 EVs.

\section{Control and Protection Comparison}

\subsection{System Model}

In order to study the system response in both nanogrids, analysis is done using lumped elements to represents the cable. Lumped element method is valid and can be used to model the system as long as the physical dimensions of the system are small compared to the wavelength of the voltage and current signals [33]. For a $3 \phi 400 \mathrm{~V}$ AC system, each phase can be represented as in Figure 7.

In this system, the lines are represented by $\mathrm{R}$ and $\mathrm{L}$ elements with stray capacitances. There are inputs and outputs assigned for the model. The inputs consist of: $I_{P V}, I_{\text {batt }}, I_{\text {grid }}$ are current from PV, ESS, and grid; while $-I_{E V}$ and $-I_{\text {load }}$ are current for EVs and the office appliances. The outputs are $V_{P V}, V_{\text {batt }}, V_{\text {grid }}, V_{E V}$, and $V_{\text {load }}$ which are the voltage at PV, ESS, grid, EV, and office appliances; $I_{L-P V}, I_{L-\text { batt }}, I_{L-\text { grid }}, I_{L-E V}, I_{L-\text { load }}$ are the current flowing at the PV, ESS, grid, EV, and office appliances' lines; $V_{C N}$ and $C_{C N}$ are the central node voltage and capacitor's size.

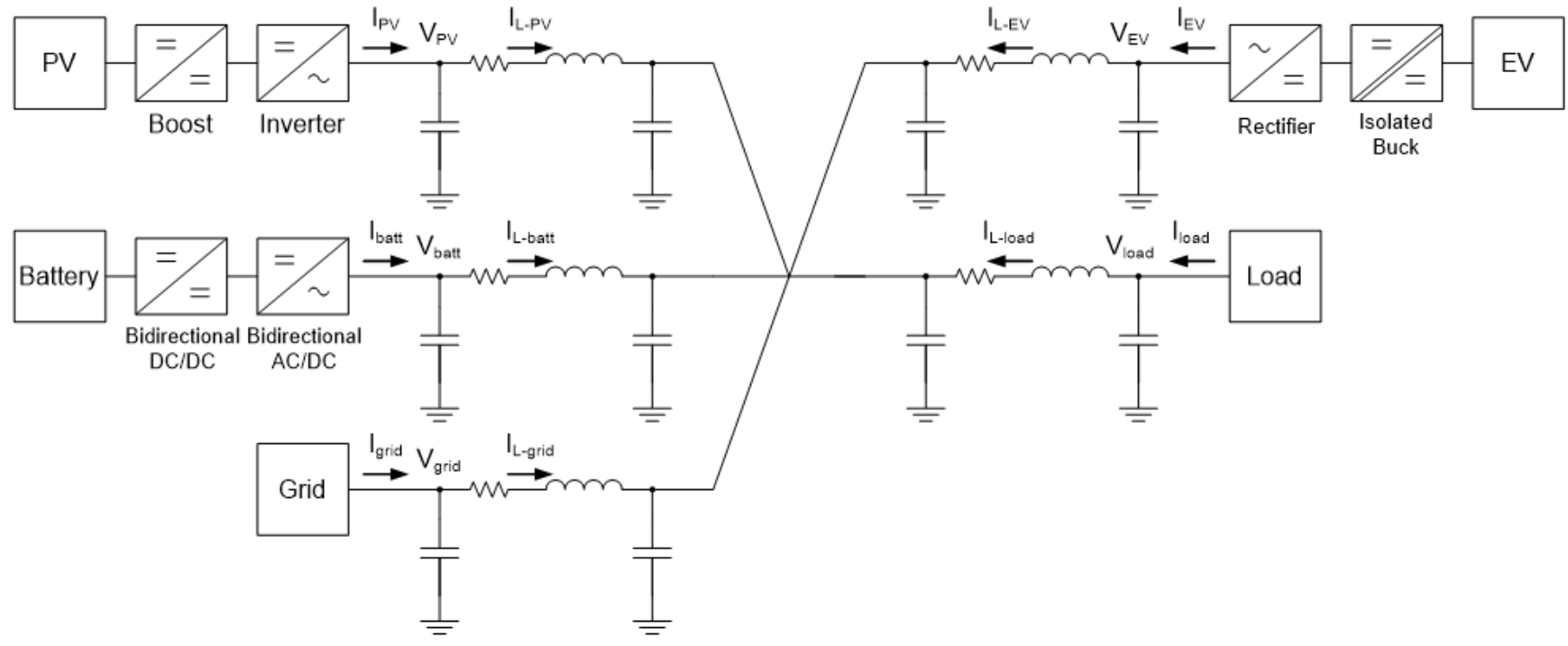

Figure 7. Single line diagram of a AC nanogrid.

In AC nanogrid, the system is directly connected to the utility grid which is assumed as a huge energy buffer. Therefore, the system is very stable from any energy production and demand changes. While in DC nanogrid, there are additional capacitors that are 
installed in the nanogrid in order to improve the system stability and also for control purposes (highlighted in Figure 8).

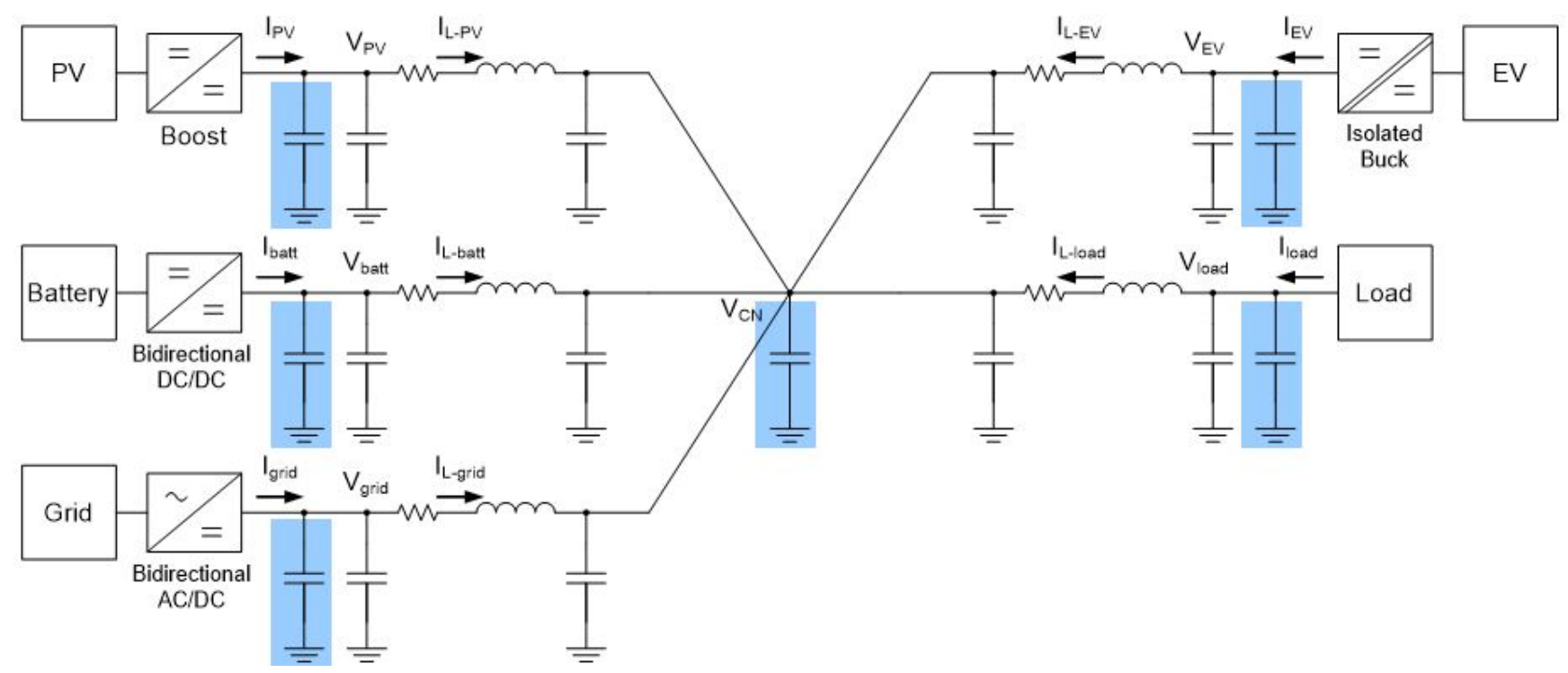

Figure 8. Single line diagram of a DC nanogrid.

These capacitors are crucial in DC nanogrid because it helps the system to maintain its stability. However, these capacitors largely affect the system response whenever there is a change in energy generation or demand condition. As previously explained, the DC nanogrid is not directly connected through the infinite grid as in AC nanogrid. Therefore, a condition change in DC nanogrid might disrupt the system operation if the converter that acts as the voltage regulator cannot restore the system voltage immediately.

The cable's resistance, inductance, and capacitance are sized based on [34,35]. The PV size is assumed to be $63 \mathrm{~kW}$ (200 PV panels) peak corresponding to 200 panels. Complete component sizes can be seen in Tables A1 and A2 in the Appendix A.

\subsection{AC Nanogrid Results}

The simulations were conducted in two conditions, i.e., power mismatch condition and short circuit fault at EV side. Initially the grid feeds a $10 \mathrm{~kW}$ load and when there are additional $10 \mathrm{~kW}$ load connected to the system, the grid can instantly provide the current required for the additional load and the there is no significant change in the voltage. In an application such as AC nanogrid, the stray capacitance is very minor and can be neglected. When a fault occurs, it is found that the system response to a fault depends on how the transformer neutral at the grid side is grounded, solidly or with a resistance, explained as follow:

$$
\begin{aligned}
& v_{B n}=v_{n}-v_{B} \\
& v_{C n}=v_{n}-v_{C}
\end{aligned}
$$

Once a fault occurs, a system which neutral transformer grounded with a resistance will have $v_{n} \neq 0$. The value of $v_{n}$ changed to:

$$
v_{n}=\frac{Z_{g}}{Z_{T}} \times v_{A}
$$

With phase change from phase A:

$$
\phi=\tan ^{-1}\left(\frac{X_{L_{T}}}{R_{T}}\right)
$$


$Z_{g}$ and $Z_{T}$ are grounding and total impedance of the faulted line, $X_{L T}$ is the grounding and total reactance of the faulted line, and $R_{T}$ is the grounding and total resistance of the faulted line. As can be seen in Figure 9b, the fault current is lower if the neutral transformer is grounded with a resistance.
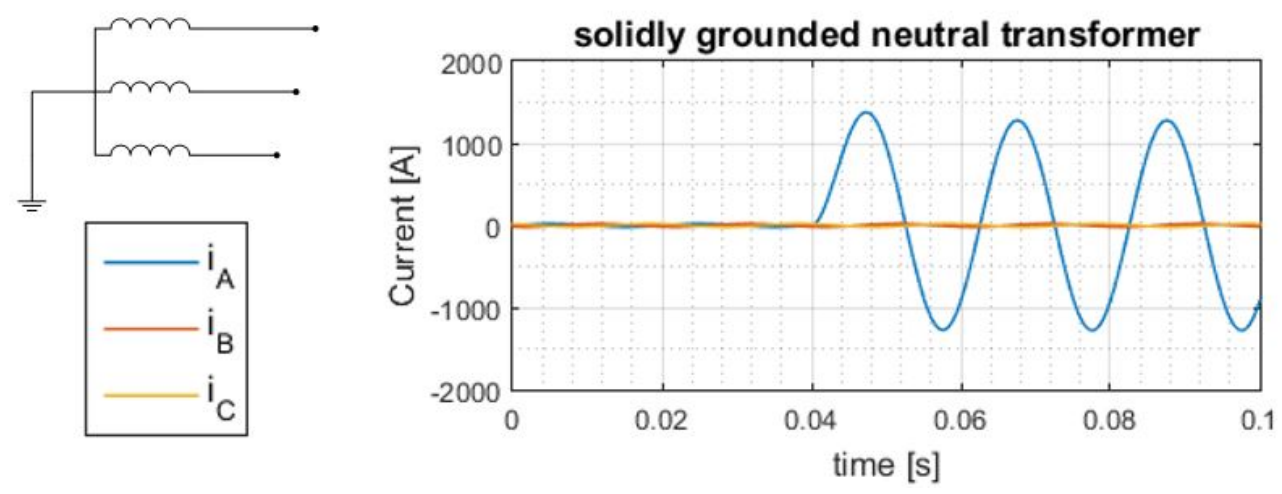

(a) Solidly grounded transformer.
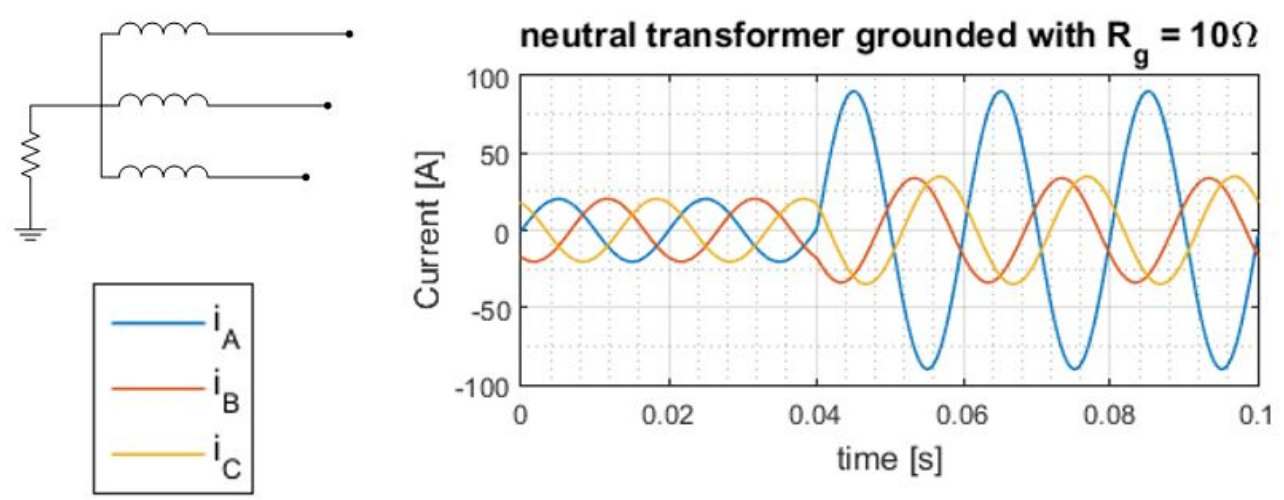

(b) Neutral transformer grounded with $\mathrm{R}=10 \Omega$.

Figure 9. Current at AC nanogrid's central node during fault for different neutral transformer grounding.

According to Figure 10b, the voltage of the healthy phases might reach line-to-line value. This is because when the neutral transformer is grounded with a resistance, once a fault occurs, the voltage at the neutral point is no longer $0 \mathrm{~V}$. This voltage increases according to the resistance and impedance along the faulted line to the neutral point. In addition, the phase to neutral voltage of the healthy phases $\left(v_{B n}\right.$ and $v_{C n}$, assuming the fault is from phase A to ground) is changed.
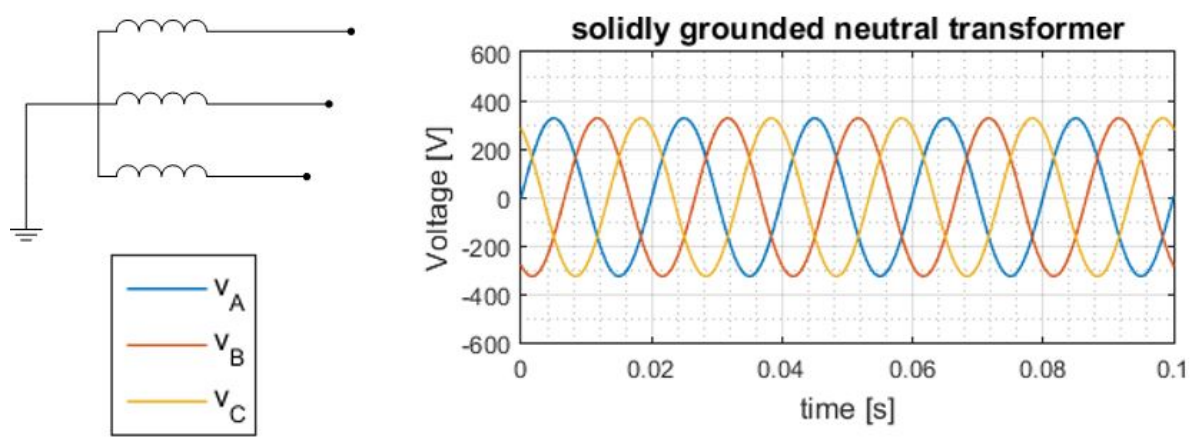

(a) Solidly grounded transformer.

Figure 10. Cont. 

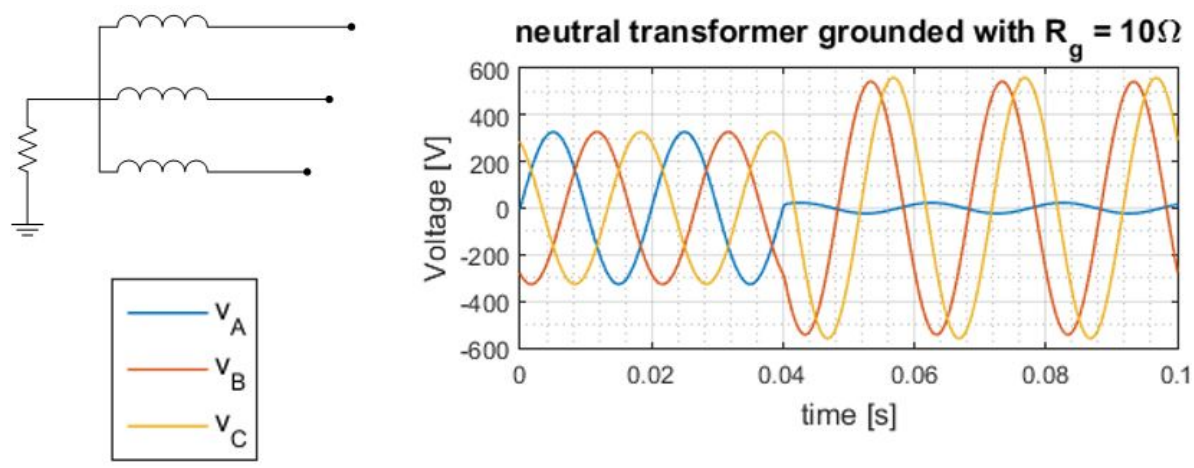

(b) Neutral transformer grounded with $\mathrm{R}=10 \Omega$.

Figure 10. Voltage at AC nanogrid's central node during fault for different neutral transformer grounding.

\subsection{Nanogrid Results}

\subsubsection{Power Variation}

In order to analyze the DC nanogrid, state-space model that was developed by [36] is adapted. The state-space is developed based on the equivalent circuit shown in Figure 11. A full DC nanogrid model is shown in Figure 12.

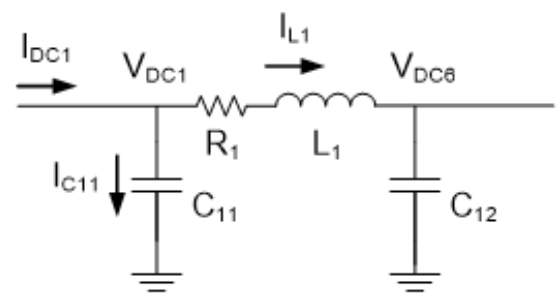

Figure 11. Equivalent circuit for the developed state-space model of a dc nanogrid.

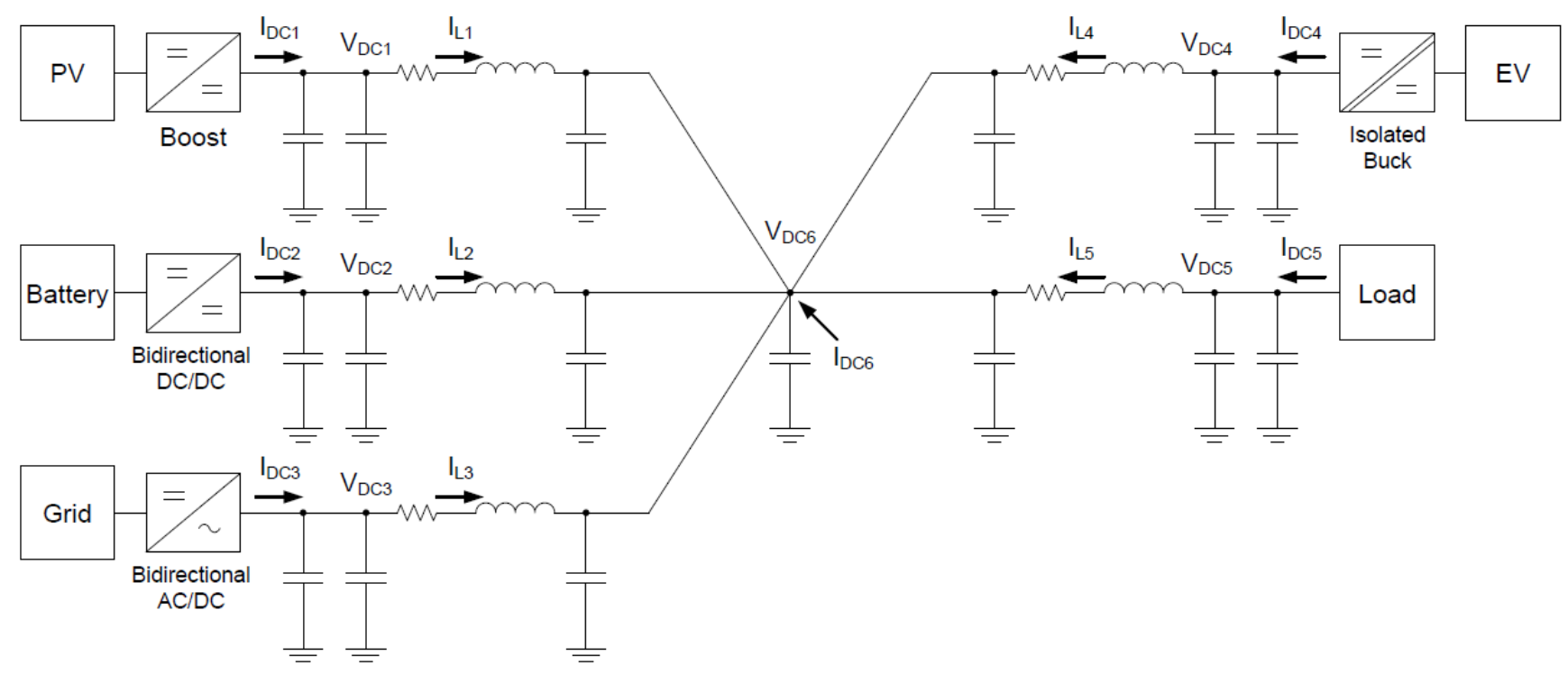

Figure 12. State space model of DC nanogrid adapted from [36].

Kirchhoff's current law:

$$
\begin{array}{r}
I_{D C 1}-I_{C 11}-I_{L 1}=0 \\
I_{D C 1}-s V_{D C 1} C_{11}-I_{L 1}=0
\end{array}
$$




$$
\begin{aligned}
s V_{D C 1} & =\frac{I_{D C 1}-I_{L 1}}{C_{11}} \\
& \Rightarrow s V_{D C n}=\frac{I_{D C n}-I_{L n}}{C_{n 1}}, n=1,2,3, \ldots 6 \\
s V_{D C 6} & =\frac{I_{D C 6}+I_{L 1}+I_{L 2}+I_{L 3}+I_{L 4}+I_{L 5}}{C_{12}+C_{22}+C_{32}+C_{42}+C_{52}} \\
C_{T} & =C_{12}+C_{22}+C_{32}+C_{42}+C_{52}
\end{aligned}
$$

Kirchoff's voltage law:

$$
\begin{gathered}
V_{D C 1}-V_{R 1}-V_{L 1}-V_{D C 6}=0 \\
V_{D C 1}-R_{1} I_{L 1}-s I_{L 1} L_{1}-V_{D C 6}=0 \\
s I_{L 1}=\frac{V_{D C 1}}{L_{1}}-\frac{V_{D C 6}}{L_{1}}-L_{1} \frac{R_{1}}{L_{1}} \\
\Rightarrow s I_{L n}=\frac{V_{D C n}}{L_{n}}-\frac{V_{D C 6}}{L_{n}}-L_{1} \frac{R_{n}}{L_{n}}, n=1,2,3, \ldots 6
\end{gathered}
$$

Based on the equations, the matrices $\mathrm{A}, \mathrm{B}, \mathrm{C}$, and D for the state space model can be determined.

$$
\begin{aligned}
& \dot{x}=A \cdot x+B \cdot u \\
& y=C \cdot x+D \cdot u
\end{aligned}
$$

Assuming there is sudden increase of PV generation in the system, for example, the PV panels are shaded and the shade is gone instantly at $t=5 \mathrm{~s}$ and results in an instant current increases to $84 \mathrm{~A}$. Then, at $\mathrm{t}=15 \mathrm{~s}$, there is an EV connected to the nanogrid and started to charge with 26 A. Figure 13 shows the DC nanogrid's voltage at PV side when there is a current injected from PV (Figure 13a) and when the EVs drawn current from the system (Figure 13b). Figure 14a,b shows the EV side's voltage at the similar conditions. It can be observed that the voltage rise/fall when a sudden current is injected/drawn from the nanogrid.

The voltage rise/fall occur because the system could not adapt with the changes as fast as the changes itself. When a current is injected to the nanogrid in a very short time, the system might not be able to sustain this instant excess current. The system require some time to use or dump the current. This instant excess current might destroy the components within the system if there is no other places to go. Therefore, an energy buffer is required in order to sustain the excess current. Capacitors can be used as the energy buffer. The instant excess current could go to the capacitors instead of to the components, hence it prevents the components failure. However, this creates a voltage rise in the capacitor.

In the other way around, when there is a current drawn from the nanogrid in a very short time, the capacitors have to act as an energy buffer. This is because the system requires longer time to provide the demanded current. Therefore, the energy is taken from the capacitors which creates a voltage drop. These rise and fall will be highest at the side where the current is injected/drawn (e.g., the highest voltage rise occurs at the PV side when the current is injected from PV).

The system need some time to restore the voltage to its initial value $(750 \mathrm{~V})$. The required time depends on the control implemented in the converter. In the simulations, PI controller is used in the grid converter in a way that the grid converter is responsible to maintain the system's voltage at $750 \mathrm{~V}$.

If the voltage changes (either rise or fall) above a certain point, the DC nanogrid operation might be disrupted. Therefore, it is important to limit the voltage changes. These can be minimized by installing larger capacitors at the input and output sides. As can be seen in Figures 13 and 14, the larger capacitor (blue, red, yellow lines) leads to lower voltage fluctuation. 


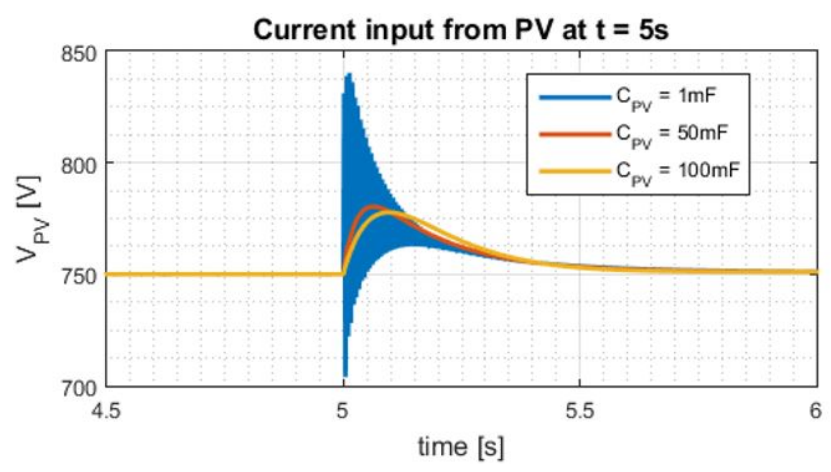

(a) Impact of 84 A current injection from PV.

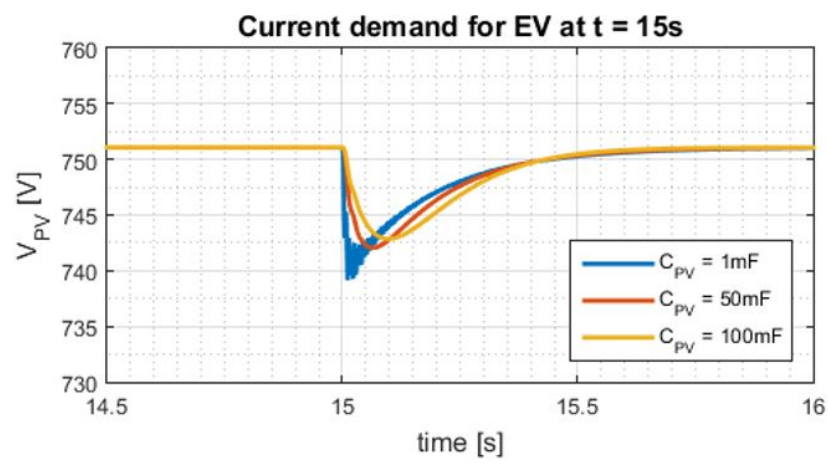

(b) Impact of 26 A current drawn by EV.

Figure 13. PV side voltage of DC nanogrid due to power mismatches.

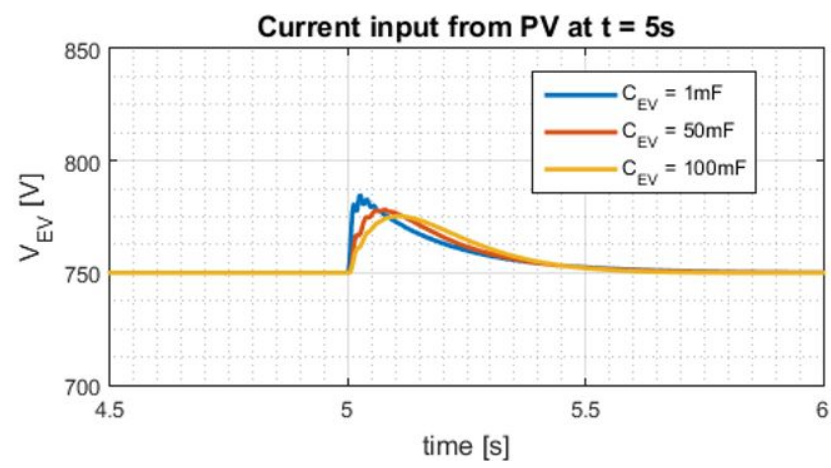

(a) Impact of 84 A current injection from PV.

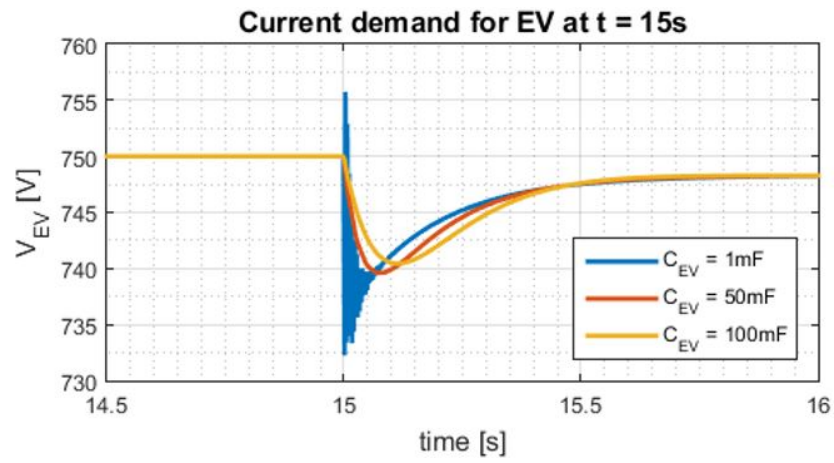

(b) Impact of $26 \mathrm{~A}$ current drawn by EV.

Figure 14. EV side voltage of DC nanogrid due to power mismatches.

Assuming that the allowed voltage fluctuation is $\pm 5 \%$ from $750 \mathrm{~V}$, based on the simulations with different sizes of capacitor, the required capacitor for each side can be 
estimated as summarized in Table 2. It is important to be noted that the higher the current rise/fall and the shorter the occurrence time require bigger capacitor in order to prevent fluctuation more than $5 \%$.

Table 2. required capacitor's size for voltage fluctuation below $\pm 5 \%$.

\begin{tabular}{cc}
\hline Capacitor on Components' Side & Required Capacitor Size \\
\hline PV & $11 \mathrm{mF}$ \\
ESS & $3 \mathrm{mF}$ \\
EV & $3 \mathrm{mF}$ \\
grid & $3 \mathrm{mF}$ \\
\hline
\end{tabular}

\subsubsection{Faults}

Even though, a larger capacitor could improve the system response, there are drawbacks on using larger capacitor in the system, i.e., higher start-up current and higher transient fault current. This can influence the designed response of the protection devices in the system.

In the other condition, assuming a fault occurs at EV's side at $t=4 \mathrm{~s}$, Figure 15 shows the DC nanogrid's voltage at EV's side and it's line current, while Figure 16 shows PV's side voltage and line current. Once a fault occurs, the voltage at all capacitors drop as the capacitors discharge. It can be seen in Figure 15a that the voltage drops instantly at the fault location. The deep voltage drop in a very short time can be an indicator of the fault location. During a short circuit fault, PV and EV converters must be able to disconnect when it senses a significant voltage drop, in order to prevent feeding the fault. Even though the components are isolated and do not feed the fault, there is still high current flowing through the line due to the capacitor discharge as shown in Figures 15b and 16b.

Larger capacitors at the central node $\left(C_{C N}\right)$ results in improved system response. At the healthy side, the voltage drops lower and slower with a higher $C_{C N}$ as can be seen in Figure 16a, but it results in higher transient current at the faulted side as shown Figure 15b. However, the transient current from the healthy side becomes lower, see Figure $16 \mathrm{~b}$. This is because most of the transient current that goes to the fault comes from the central capacitor $\left(C_{C N}\right)$. The transient at the line of the faulted side is high because all the capacitors within the system are discharged to the fault.

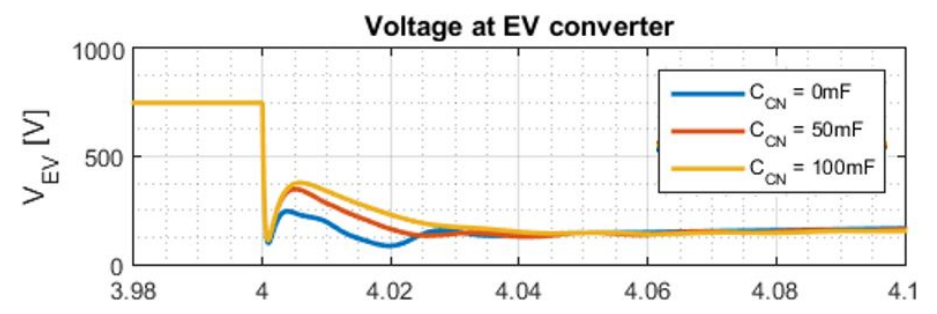

(a) EV-side voltage.

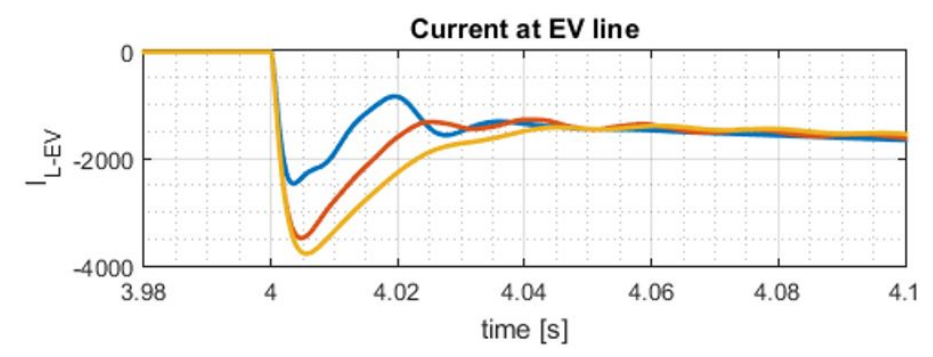

(b) EV-side Line current.

Figure 15. Response with EV-side fault. 


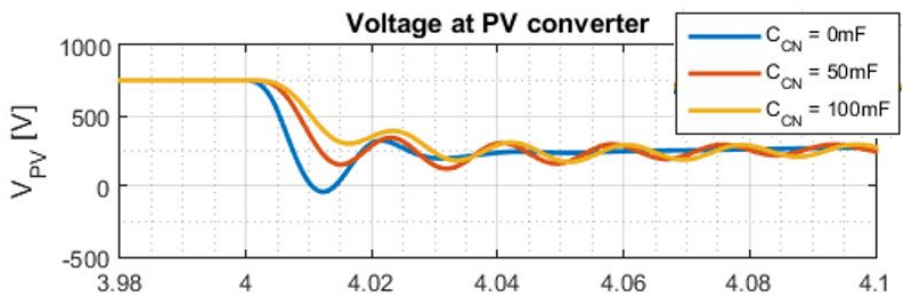

(a) PV-side voltage.

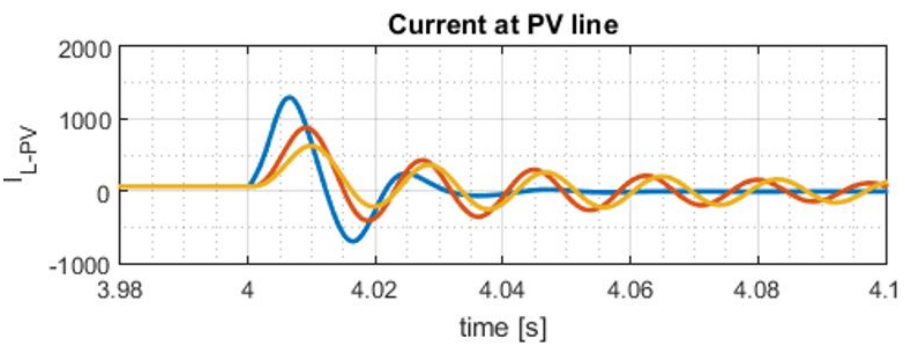

(b) PV-side Line current.

Figure 16. PV-Side response with EV-side fault.

The grid voltage $\left(V_{\text {grid }}\right)$ is regulated by connected converter. Therefore, once a fault occurs, the nanogrid's voltage drops, and the grid tries to restore the voltage by injecting a higher current into the nanogrid (Figure 17). Since these high currents may damage the grid's converter, this should be avoided. The current at grid line $\left(I_{L-\text { grid }}\right)$ is slightly higher than the current coming from gird $\left(I_{\text {grid }}\right)$ because the discharge of the capacitor at grid's side.

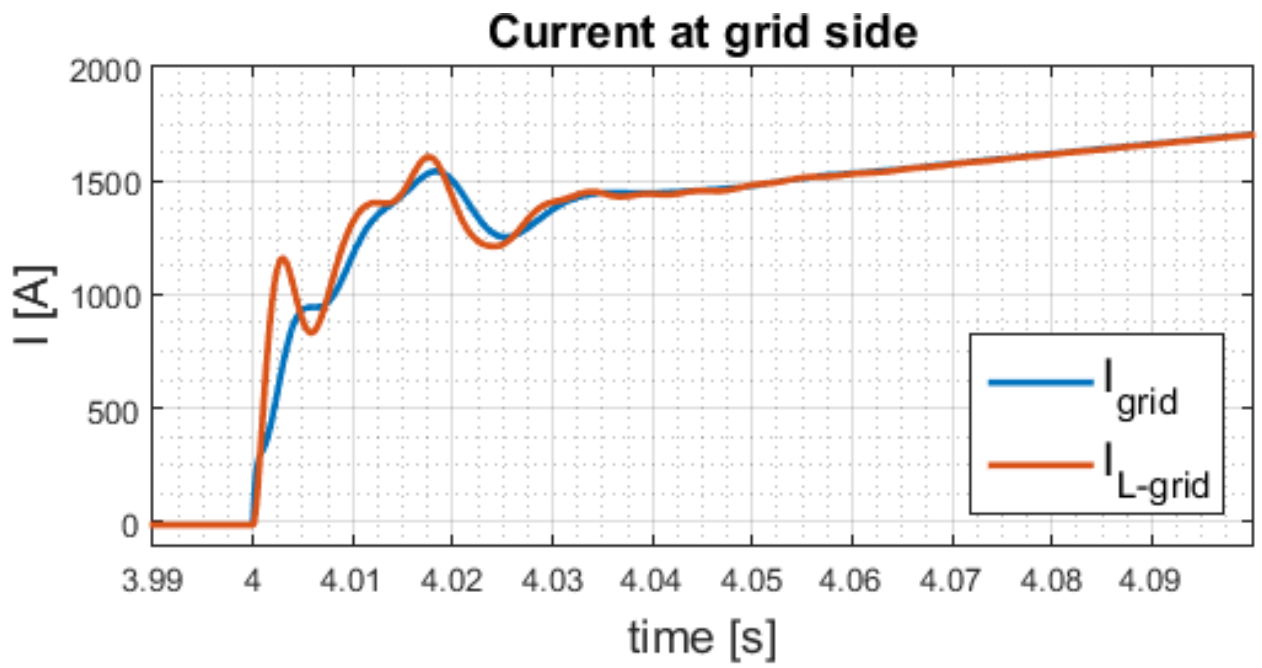

Figure 17. Grid current during EV-side fault.

Disconnecting the grid converter will result in a black-out in the office because the office appliances will no longer have power and the nanogrid voltage will collapse. The better action is to isolate the faulted line, in this case the EV line, hence, the office appliances and the grid will still be connected. Therefore, it is important for protection devices to be able to isolate the fault before the grid's converter is disconnected. It is also important for the grid's converter to be able to withstand a huge current during fault before the protection device isolates the faulted line.

Simulations at each side of the system (PV, EV, ESS, office appliances, and grid) were conducted in order to obtain the required interruption time for every fault location. The correlation of fault location, central capacitor size, and required interruption time before the current from the grid exceeds $400 \mathrm{~A}$ is summarized in Table 3. 
Table 3. Required interruption time before the grid's current exceeds $400 \mathrm{~A}$.

\begin{tabular}{cccc}
\hline Fault at & \multicolumn{3}{c}{ Required Interruption Time [ms] } \\
& $C_{C N}=\mathbf{0 ~} \mathbf{~ F ~}$ & $C_{C N}=\mathbf{5 0 ~ \mathbf { ~ F }}$ & $C_{C N}=\mathbf{1 0 0 ~} \mathbf{~ F F}$ \\
\hline PV & 3 & 6.5 & 9 \\
EV & 2 & 5 & 6.2 \\
ESS & 0.5 & 4 & 6 \\
Office appliances & 3 & 7.5 & 11 \\
Grid & 0.3 & 3.3 & 5.1 \\
\hline
\end{tabular}

The required interruption time is smallest when the short circuit fault occurs at the grid side because the fault current comes from the grid. In this case, the grid has to be disconnected from the system in order to prevent a huge current goes through the grid converter. The further the fault location from the grid, the longer the required time for the fault current before it reaches $400 \mathrm{~A}$. This is because of the resistance and inductance along the lines.

Based on the results and analysis obtained in the previous section, the difference between $\mathrm{AC}$ and DC nanogrids in an office building with PV and EVs along with the fault behavior can be summarized as in Table 4, including the experiment results from [13,19,20,37-39].

Table 4. Protection mechanisms comparison

\begin{tabular}{|c|c|c|}
\hline & AC Nanogrid & DC Nanogrid \\
\hline Presence of capacitors & $\begin{array}{l}\text { Present only due to parasitic connection } \\
\text { with earth. Does not give significant } \\
\text { effect on system response }\end{array}$ & $\begin{array}{l}\text { Required for control and stability purpose. Lowers voltage } \\
\text { oscillations during power mismatch. Highly affect the fault } \\
\text { current and voltage response. Bigger capacitors improve the } \\
\text { system response but it causes high start-up, fault transient } \\
\text { current, and more expensive. }\end{array}$ \\
\hline Fault interruption time & $\begin{array}{c}\text { Required time: } 40 \mathrm{~ms} \text {. The longer it takes } \\
\text { to interrupt the fault, the higher the fault } \\
\text { current. }\end{array}$ & $\begin{array}{l}\text { Required time: } 4 \mathrm{~ms} \text {. The longer the fault's interruption, } \\
\text { not only the high current, but also the high voltage rise will } \\
\text { occur once the fault is isolated. }\end{array}$ \\
\hline Arc protection devices & Not required & Highly required due to the absence of zero crossing. \\
\hline $\begin{array}{l}\text { Suitable protection } \\
\text { devices }\end{array}$ & Fuses and mechanical circuit breaker & $\begin{array}{l}\text { Solid state switch. Additional L can be used to have lower } \\
\text { voltage drop rate but it reduces the system response. }\end{array}$ \\
\hline Fault current & $I_{F_{A C}}=\frac{V_{F}}{R+j \omega L}$ & $I_{F_{D C}}=\frac{V_{F}}{R}$ \\
\hline Transient fault current & $\begin{array}{l}\text { The transient peak is not present in AC } \\
\text { side if the neutral transformer is } \\
\text { grounded. }\end{array}$ & $\begin{array}{l}\text { Transient current always present regardless of the } \\
\text { grounding strategy and highly dependent on the } \\
\text { capacitors' size }\end{array}$ \\
\hline
\end{tabular}

\section{Conclusions}

DC nanogrid is most likely to give higher efficiency than AC as long as the energy that being exchanged with the AC grid is low and the EV demands are higher than office appliance. For same cable resistance, DC cable has higher power handling capability than AC. Less power converters are needed and higher reliability in DC owing to lesser components. These result in higher saving which is important for an application in an office building. Even though DC might have higher capital cost than AC nanogrid, by having more annual saving, eventually, the capital cost difference can be counterbalanced.

The behavior of DC system is more complex; it requires buffer capacitors to support the system control. However, there are drawbacks on using buffer capacitors, i.e., higher transient fault current, higher start up current, and the expensive cost of big capacitors. Furthermore, additional protection devices is required in order to compensate the transient response and it has to be able to interrupt the fault current fast. The longer it takes to isolate 
the fault leads to deeper voltage drop. This will result in a higher current and voltage rise once the fault is isolated.

These results are summarized in the following Table 5.

Table 5. AC and DC nanogrid comparison.

\begin{tabular}{ccc}
\hline & AC Nanogrid & DC Nanogrid \\
System efficiency & $\begin{array}{c}\text { Higher at high grid energy } \\
\text { exchange and EV demands are } \\
\text { less dominant than office } \\
\text { appliances. }\end{array}$ & $\begin{array}{c}\text { Higher at low grid energy } \\
\text { exchange and EV demands are } \\
\text { more dominant than } \\
\text { office appliances. }\end{array}$ \\
\hline Impact of ESS & $\begin{array}{c}\text { More losses due to more } \\
\text { conversion steps when more } \\
\text { excess PV is stored in ESS. }\end{array}$ & $\begin{array}{c}\text { Similar trend with AC nanogrid } \\
\text { but lower losses due to lower } \\
\text { conversion steps to ESS. }\end{array}$ \\
\hline & $\begin{array}{c}\text { Transient fault current depends } \\
\text { on transformer grounding, lower } \\
\text { fault current. }\end{array}$ & $\begin{array}{c}\text { More complex, may require buffer } \\
\text { capacitor and fast interruption } \\
\text { protection device. }\end{array}$ \\
\hline
\end{tabular}

Based on this study, the following are suggestions for future improvements and research,

- $\quad$ Fast fault interruption. As observed in Section 4.3.2, fast fault interruption time is necessary for DC interconnection. Currently, solid state switches is used for fast interruption and it is more expensive than the conventional circuit breakers. Finding a method that could provide fast interruption and economically viable will make DC nanogrid more attractive.

- Monopolar vs. Bipolar. The behavior of bipolar DC system and the impact of fullrated voltage and neutral line imbalance to the appliances have not been covered in this study.

- $\quad$ Addressing high current during start-up or fault. In DC system, the bidirectional AC/DC converter which connects the grid is important because it regulates the system. During start-up or fault, this converter has to withstand a high current before the fault is isolated. Therefore, attenuating the current or improving the capability of bidirectional AC/DC is important.

Author Contributions: Methodology, I.S.; investigation, I.S.; supervision, G.R.C.M.; writing—review and editing, A.S.; project administration, P.B. All authors have read and agreed to the published version of the manuscript.

Funding: This research received no external funding.

Institutional Review Board Statement: Not applicable.

Informed Consent Statement: Not applicable.

Conflicts of Interest: The authors declare no conflict of interest.

\section{Appendix A}

AC nanogrid is using $3 \phi 400 \mathrm{~V}$ while DC nanogrid uses $750 \mathrm{~V}$. Based on the voltage level, the peak current for both nanogrids are slightly different. Therefore, the cables that are used for the nanogrids have similar specifications as presented in Tables A1 and A2. 
Table A1. Cable types.

\begin{tabular}{ccccc}
\hline \multirow{2}{*}{ No } & \multirow{2}{*}{ Components } & \multicolumn{2}{c}{ Peak Current [A] } & \multirow{2}{*}{ Cable Type } \\
& & AC & DC & \\
\hline 1 & PV & 90.93 & 84.00 & AWG 2 \\
2 & ESS & 33.05 & 30.53 & AWG 8 \\
3 & Grid & 60.04 & 55.47 & AWG 4 \\
4 & Office & 31.75 & 29.33 & AWG 8 \\
5 & appliances & 28.29 & 26.13 & AWG 10 \\
\hline
\end{tabular}

Table A2. Components' sizes.

\begin{tabular}{ccccc}
\hline No & Components & Total $\mathbf{R}[\mathbf{m} \Omega]$ & $\begin{array}{c}\text { Cable's Specifications } \\
\text { Total } \mathbf{H}[\boldsymbol{\mu H}]\end{array}$ & Total C [pF] \\
\hline 1 & PV & 25.63 & 876.1 & 1118 \\
2 & ESS & 30.91 & 247.5 & 237.6 \\
3 & Grid & 12.22 & 233.5 & 286.2 \\
4 & Office appliances & 103.1 & 945.5 & 792.1 \\
5 & EV & 65.54 & 351.28 & 339.12 \\
\hline
\end{tabular}

\section{References}

1. Dincer, I. Renewable energy and sustainable development: A crucial review. Renew. Sustain. Energy Rev. 2000, 4, 157-175. [CrossRef]

2. IRENA. Renewable Energy Capacity Statistics 2015; Technical Report; IRENA: Abu Dhabi, United Arab Emirates, 2015. [CrossRef]

3. REN21. Renewables 2015 Global Status Report; Technical Report; L Renewable Energy Policy Network for the 21st Century: Paris, France, 2015.

4. Shekhar, A.; Prasanth, V.; Bauer, P.; Bolech, M. Economic viability study of an on-road wireless charging system with a generic driving range estimation method. Energies 2016, 9, 76. [CrossRef]

5. Mouli, G.C.; Bauer, P.; Zeman, M. System design for a solar powered electric vehicle charging station for workplaces. Appl. Energy 2016, 168, 434-443. [CrossRef]

6. Chandra Mouli, G.R.; Kefayati, M.; Baldick, R.; Bauer, P. Integrated PV Charging of EV Fleet Based on Energy Prices, V2G, and Offer of Reserves. IEEE Trans. Smart Grid 2019, 10, 1313-1325. [CrossRef]

7. Venugopal, P.; Shekhar, A.; Visser, E.; Scheele, N.; Mouli, G.R.C.; Bauer, P.; Silvester, S. Roadway to self-healing highways with integrated wireless electric vehicle charging and sustainable energy harvesting technologies. Appl. Energy 2018, 212, 1226-1239. [CrossRef]

8. Deboever, J.; Peppanen, J.; Maitra, A.; Damato, G.; Taylor, J.; Patel, J. Energy Storage as a Non-Wires Alternative for Deferring Distribution Capacity Investments. In Proceedings of the 2018 IEEE/PES Transmission and Distribution Conference and Exposition (T D), Denver, CO, USA, 16-19 April 2018; pp. 1-5. [CrossRef]

9. Faisal, M.; Hannan, M.A.; Ker, P.J.; Hussain, A.; Mansor, M.B.; Blaabjerg, F. Review of Energy Storage System Technologies in Microgrid Applications: Issues and Challenges. IEEE Access 2018, 6, 35143-35164. [CrossRef]

10. Yang, Y.; Bremner, S.; Menictas, C.; Kay, M. Battery energy storage system size determination in renewable energy systems: A review. Renew. Sustain. Energy Rev. 2018, 91, 109-125. [CrossRef]

11. Dragicevic, T.; Wheeler, P.; Blaabjerg, F. (Eds.) DC Distribution Systems and Microgrids, 1st ed.; Institution of Engineering and Technology: London, UK, 2018; Volume 1. [CrossRef]

12. Dragičević, T.; Lu, X.; Vasquez, J.C.; Guerrero, J.M. DC Microgrids-Part II: A Review of Power Architectures, Applications, and Standardization Issues. IEEE Trans. Power Electron. 2016, 31, 3528-3549. [CrossRef]

13. Emhemed, A.; Burt, G. The effectiveness of using IEC61660 for characterising short-circuit currents of future low voltage DC distribution networks. In Proceedings of the 22nd International Conference and Exhibition on Electricity Distribution (CIRED 2013), Stockholm, Sweden, 10-13 June 2013; pp. 1-4. [CrossRef]

14. Saputra, F.W.Y.; Aripriharta.; Fadlika, I.; Mufti, N.; Wibowo, K.H.; Jong, G.J. Efficiency Comparison between DC and AC Grid Toward Green Energy In Indonesia. In Proceedings of the 2019 IEEE International Conference on Automatic Control and Intelligent Systems (I2CACIS), Shah Alam, Malaysia, 29 June 2019; pp. 129-134. [CrossRef]

15. Mackay, L.; van der Blij, N.H.; Ramirez-Elizondo, L.; Bauer, P. Toward the Universal DC Distribution System. Electr. Power Components Syst. 2017, 45, 1032-1042. [CrossRef]

16. Mouli, G.R.C.; Bauer, P.; Zeman, M. Comparison of system architecture and converter topology for a solar powered electric vehicle charging station. In Proceedings of the 2015 9th International Conference on Power Electronics and ECCE Asia (ICPE-ECCE Asia), Seoul, Korea, 1-5 June 2015; pp. 1908-1915. [CrossRef] 
17. Meliopoulos, A.P.S.; Martin, M.A. Calculation of secondary cable losses and ampacity in the presence of harmonics. IEEE Trans. Power Deliv. 1992, 7, 451-459. [CrossRef]

18. Dastgeer, F.; Kalam, A. Efficiency comparison of DC and AC distribution systems for distributed generation. In Proceedings of the 2009 Australasian Universities Power Engineering Conference, Adelaide, Australia, 27-30 September 2009; pp. 1-5.

19. ABB. Technical Application Papers No.14 Faults in LVDC Microgrids with Front-End Converters; ABB: Zürich, Switzerland, 2015.

20. Estes, H.B.; Kwasinski, A.; Hebner, R.E.; Uriarte, F.M.; Gattozzi, A.L. Open series fault comparison in AC amp; DC microgrid architectures. In Proceedings of the 2011 IEEE 33rd International Telecommunications Energy Conference (INTELEC), Amsterdam, The Netherlands, 9-13 October 2011; pp. 1-6. [CrossRef]

21. Justo, J.J.; Mwasilu, F.; Lee, J.; Jung, J.W. AC-microgrids versus DC-microgrids with distributed energy resources: A review. Renew. Sustain. Energy Rev. 2013, 24, 387-405. [CrossRef]

22. Barco, H.E.C. Hybrid Renewable Energy Systems, Control Strategy \& Project Evaluation. Ph.D. Thesis, Department Intelligent Electrical power Grids, Delft, The Netherlands, 2013.

23. Shekhar, A.; Ramírez-Elizondo, L.; Bandyopadhyay, S.; Mackay, L.; Bauera, P. Detection of series arcs using load side voltage drop for protection of low voltage DC systems. IEEE Trans. Smart Grid 2017, 9, 6288-6297. [CrossRef]

24. Liu, Z.; Shekhar, A.; Ramírez-Elizondo, L.; Bauer, P. Characterization of series arcs in LVdc microgrids. In Proceedings of the 2017 IEEE Second International Conference on DC Microgrids (ICDCM), Nuremburg, Germany, 27-29 June 2017; pp. $297-301$.

25. Gerber, D.L.; Vossos, V.; Feng, W.; Marnay, C.; Nordman, B.; Brown, R. A simulation-based efficiency comparison of AC and DC power distribution networks in commercial buildings. Appl. Energy 2018, 210, 1167-1187. [CrossRef]

26. Mocanu, E.; Nguyen, P.H.; Gibescu, M.; Kling, W.L. Comparison of machine learning methods for estimating energy consumption in buildings. In Proceedings of the 2014 International Conference on Probabilistic Methods Applied to Power Systems (PMAPS), Durham, UK, 7-10 July 2014; pp. 1-6. [CrossRef]

27. Mackay, L.; Ramirez-Elizondo, L.; Bauer, P. DC ready devices-Is redimensioning of the rectification components necessary? In Proceedings of the 16th International Conference on Mechatronics-Mechatronika 2014, Brno, Czech Republic, 3-5 December 2014; pp. 1-5.

28. Wu, T.; Chen, Y.; Yu, G.; Chang, Y. Design and development of dc-distributed system with grid connection for residential applications. In Proceedings of the 8th International Conference on Power Electronics-ECCE Asia, Jeju, Korea, 30 May-3 June 2011; pp. 235-241.

29. Wunder, B.; Ott, L.; Szpek, M.; Boeke, U.; Weiß, R. Energy efficient DC-grids for commercial buildings. In Proceedings of the 2014 IEEE 36th International Telecommunications Energy Conference (INTELEC), Vancouver, BC, Canada, 28 September-2 October 2014; pp. 1-8.

30. Torreglosa, J.P.; García-Triviño, P.; Fernàndez-Ramirez, L.M.; Jurado, F. Decentralized energy management strategy based on predictive controllers for a medium voltage direct current photovoltaic electric vehicle charging station. Energy Convers. Manag. 2016, 108, 1-13. [CrossRef]

31. Baboli, P.T.; Bahramara, S.; Moghaddam, M.P.; Haghifam, M.R. A mixed-integer linear model for optimal operation of hybrid AC-DC microgrid considering Renewable Energy Resources and PHEVs. In Proceedings of the 2015 IEEE Eindhoven PowerTech, Eindhoven, The Netherlands, 29 June-2 July 2015; pp. 1-5. [CrossRef]

32. Sulaeman, I.; Vega-Garita, V.; Mouli, G.R.C.; Narayan, N.; Ramirez-Elizondo, L.; Bauer, P. Comparison of PV-battery architectures for residential applications. In Proceedings of the 2016 IEEE International Energy Conference (ENERGYCON), Leuven, Belgium, 4-8 April 2016; pp. 1-7. [CrossRef]

33. Van der Sluis, L. Transients in Power Systems; John Wiley \& Sons, LTD.: Hoboken, NJ, USA, 2001.

34. Panduit. Electrical Wire Sizes Selection Guide. 2011. Available online: http://www.panduit.com/heiler/SelectionGuides/WWWASG03\%20Electrical\%20Wire\%20Sizes-WEB\%207-7-11.pdf (accessed on 9 September 2021).

35. Rosa, E.B. The Self and Mutual Inductances of Linear Conductors. In Bulletin of the Bureau of Standards; Government Printing Office: Washington, DC, USA, 1908; Volume 4, pp. 301-344.

36. Noriega, B.E.; Pinto, R.T.; Bauer, P. Sustainable DC-microgrid control system for electric-vehicle charging stations. In Proceedings of the 2013 15th European Conference on Power Electronics and Applications (EPE), Lille, France, 2-6 September 2013; pp. 1-10. [CrossRef]

37. Carminati, M.; Ragaini, E.; Tironi, E. DC and AC ground fault analysis in LVDC microgrids with energy storage systems. In Proceedings of the 2015 IEEE 15th International Conference on Environment and Electrical Engineering (EEEIC), Rome, Italy, 10-13 June 2015; pp. 1047-1054. [CrossRef]

38. Schroder, S.; Meyer, C.; Doncker, R.W.D. Solid-state circuit breakers and current-limiting devices for medium-voltage systems. In Proceedings of the VIII IEEE International Power Electronics Congress, Guadalajara, Mexico, 20-24 October 2002; pp. 91-95. [CrossRef]

39. Meyer, C.; Schroder, S.; Doncker, R.W.D. Design of solid-state circuit breakers for medium-voltage systems. In Proceedings of the 2003 IEEE PES Transmission and Distribution Conference and Exposition (IEEE Cat. No.03CH37495), Dallas, TX, USA, 7-12 September 2003; Volume 2, pp. 798-803. [CrossRef] 